\title{
The COVID-19 pandemic in children and young people during 2020-2021: A complex discussion on vaccination
}

\section{Igor Rudan ${ }^{1}$, Davies Adeloye ${ }^{1}$, Vittal Katikireddi², Josie Murray ${ }^{3}$, Colin Simpson ${ }^{4,5}$, Syed Ahmar Shah ${ }^{5}$, Chris Robertson ${ }^{6}$, Aziz Sheikh ${ }^{5}$; EAVE II collaboration}

\author{
${ }^{1}$ Centre for Global Health, Usher Institute, The University of Edinburgh, Edinburgh, UK \\ ${ }^{2} \mathrm{MRC/CSO}$ Social \& Public Health Sciences Unit, Glasgow, UK \\ ${ }^{3}$ COVID-19 Surveillance Lead, Public Health Scotland, Fife, UK \\ ${ }^{4}$ School of Health, Wellington Faculty of Health, Victoria University of Wellington, New Zealand \\ ${ }^{5}$ Usher Institute, The University of Edinburgh, Edinburgh, UK \\ ${ }^{6}$ Department of Mathematics and Statistics, University of Strathclyde, Glasgow, UK and Public Health Scotland, Glasgow, UK
}

I $\mathrm{n}$ this, second of the two editorials on children and young people (CYP) in the COVID-19 pandemic, we focus on the complex discussion on vaccination of minors against severe acute respiratory syndrome coronavirus 2 (SARS-CoV-2). Vaccination of children and young people (CYP) against COVID-19 remains highly debated, with considerable policy divergence internationally. Vaccinating younger age groups was not an initial plan when the original variant of the SARS-CoV-2 virus emerged, because CYP seemed mildly affected by COVID-19 when compared to adults, as discussed in the first editorial. However, new mutations led to increased transmission of SARS-CoV-2. This led to an increase in the population threshold of vaccination coverage required for prevention of viral spread, possibly to levels above $80 \%$ vaccine uptake in the whole population. Also, due to the successful roll-out of vaccination to older and at-risk populations, the virus began to circulate in greater numbers amongst younger populations, which became a new concern. An important element was also the issue of broader harms, such as educational disruption, which can also become a determinant of long-term health. A broader perspective weighted the long-term impact across multiple dimensions of human life and shorter-term health concerns. In addition, increasing awareness of the possible rare complications of COVID-19 in CYP, such as Multisystem Inflammatory Syndrome in Children (MIS-C), and the "long COVID" syndrome prompted the scientific study and comparison of the risks of disease vs the safety of vaccination, even among the very young [1,2].

As a result, pharmaceutical and biotechnological companies started testing the efficacy and safety of vaccines in adolescents and children. In parallel, an increasing number of countries started to roll out vaccines to under-18-year-olds to protect themselves from the new and ever-more-transmissible variants. The first studies on the uptake, effectiveness and safety of the vaccines in children at the population level were conducted in 2021 [1-4]. This editorial aims to review the development of research on vaccinating CYP: the circumstances, rationale and evidence that was used to extend the vaccine programme to CYP during the COVID-19 pandemic in some countries. The paper is based on the information available until December 1st, 2021. 


\section{DISCUSSION ON ETHICAL ASPECTS OF VACCINATING MINORS}

The key points of the initial discussion in the literature have focused on the issue of equipoise in children balancing risk and benefits for an individual child, which included social, as well as medical outcomes, vs the broader benefits and harms to society. An additional layer of concern was expressed towards considering risks and benefits among particularly vulnerable children. Then, the practicalities of licensing and the discussion of mandated vaccination emerged as the third major theme [3-17]. It emerged from previous literature that, to enrol children in any clinical trials, knowledge gaps on COVID-19 would need to be addressed. Then, the effects of immune maturation should be well understood from birth to the age of 18 years [7].

The discrepancy in the views arose because many questions about children were initially unanswered, such as their role in the transmission, the effectiveness of the vaccine in reducing transmission, and the expected benefits to any vaccinated child. When deciding on approving and mandating a novel vaccine for a disease that is not a major threat to children, the decision becomes quite difficult, especially when relevant underlying scientific evidence on disease severity, vaccine safety and vaccine effectiveness is still to be gathered and confirmed without reasonable doubt. Alternatives and the levels of coercion associated with each should also be carefully considered. When planning vaccination programmes, difficult issues of balancing between selfinterest and duty to others also come into consideration. Requirements outlined for mandatory vaccination against COVID-19 in children, from an ethical perspective, should include information on whether the disease is a sufficient threat, positive comparative expected usefulness of vaccination, and proportionate coercion [6]. The case for the mandatory vaccine in children may also be considered for influenza vaccination during the COVID-19 pandemic [6].

Given that COVID-19 is typically a mild disease among minors, a risk-benefit ratio required to enrol children in vaccine trials and any other clinical trials should be carefully considered. There are differences in innate and adaptive immunity between children and adolescents, which may affect vaccine efficacy [7]. Early ethical considerations concluded that there are strong ethical reasons to vaccinate the young to protect the old, as well as protect children themselves. Thereby, children should be protected both from the health and social consequences of infection, and that this argument should also be considered in policy-making [4,5,913]. Ethical concerns would need to be carefully documented and addressed. Notably, specific situations and needs of children with developmental disorders and chronic conditions should be analysed, health inequities considered [8], and vaccine hesitancy assessed in each society and community before attempting vaccination programmes [7]. Considerations about possibly vaccinating particularly vulnerable children have increased interest in ethical and legal aspects of vaccinating minors and ensuring consent/assent is appropriately taken.

There was also interest in whether vaccination against COVID-19 in children should ever become mandatory. The literature about school mandates is abundant. However, a body of common understanding of whether it is appropriate to mandate a specific vaccine is scarce. An ethical framework to consider when should school mandates apply suggests that a principled way to think of a vaccine mandate is to consider it as an intersection of competing values while examining the factors that strengthen or weaken each of the values under the circumstances. The framework should take into account the values of autonomy, beneficence, utilitarianism, justice, and non-maleficence because they could all be affected by mandating immunization [3,14-16].

When considering pediatric off-label use of COVID-19 vaccines from an ethical and legal point, some authors contextualized ethical and legal precedents regarding off-label use and offered an analysis of the ethical permissibility of, and considerations for, pediatric off-label COVID-19 vaccination based on individual benefits, risks, and available alternatives. Their analysis challenged the ethics of a blanket prohibition on off-label pediatric COVID-19 vaccination. The argument is that it limits clinicians' ability to provide care that they determine is clinically and ethically appropriate. Inevitably, COVID-19 "creates population-level ethical considerations that are at times in tension with individual health interests" [17].

\section{DISCUSSION OF INCLUSION OF CHILDREN AND YOUNG PEOPLE IN VACCINE TRIALS AND VACCINATION PROGRAMMES AGAINST COVID-19}

Lack of clearly effective treatment, the emergence of Multisystem Inflammatory Syndrome in Children (MISC), the presence of particularly vulnerable CYP in the population, the many unknowns of the burden of "long COVID-19", and the improved understanding of ethical and legal aspects of vaccinating minors against COVID-19 have all led to an intense, vigorous and still ongoing debate in the scientific literature on whether minors should also be mass-vaccinated in the COVID-19 pandemic [18-102]. Parents were called upon by experts 
to do their "due diligence" and continue to inform themselves in making the best decision for their children [19]. Some authors were quite clear in pointing out that delaying vaccine clinical trials in children will also delay global recovery from COVID-19 and that the consequence will be an unnecessary prolongation of negative impacts on children's education, health, and emotional well-being, while also denting hopes for equitable access to opportunities for development and social success [21,25].

Vaccine platforms were analysed and practical considerations for their potential use in children were reviewed, along with the ethical aspects [22]. Modelling was done to assess the potential impact of vaccinating children on the course of the pandemic $[43,90]$. Concerns were also expressed about the negative effects of the pandemic on routine childhood vaccine coverage, especially in many places of the world where they are most needed to protect the most underprivileged children from vaccine-preventable diseases [22]. This was not only relevant to low- and middle-income countries (LMICs), but also applied to some areas of the high-income world, such as Texas, USA, where a 47\%-58\% decline in immunization rates was reported between 2019 and 2020 in children 5-16 months old [44].

Reasons for and against vaccinating minors were carefully considered in many of the scientific papers on this issue. For example, the European Centre for Disease Prevention and Control (ECDC) issued a report on June 1, 2021, which contained important considerations for public health authorities in the European Union (EU) and European Economic Area (EEA), focused on vaccinating children and adolescents. It suggested that the decisions need to be made after considering the uptake in older age groups, the incidence of COVID-19 in the general population, and practical issues concerning availability and access to vaccines globally. The ECDC report stated that minors "would experience few direct benefits from being vaccinated; rather, the goal would be to increase overall population immunity and reduce transmission" [48,102].

Nevertheless, evidence on the role of this age group in transmission has been rather patchy and not always pointing to the same conclusion, depending on the population and the wave that was studied, and the antiepidemic measures that were in place. And even within those who were $<18$ years old, there seemed to be an age gradient, with younger children seemingly less susceptible to infection and less likely to pass it on, suggesting vaccination of older age groups first [48]. In terms of priorities for protection, children with cancer, disorders of the heart, diabetes, hypertension, neurological conditions, asthma or kidney disease, with a risk of hospitalisation, would be prioritised - but again, the evidence was limited because they were already being shielded very well $[45,48]$.

Besides those over-arching arguments of reducing the overall transmission to protect the elderly who are most vulnerable, and protecting the children who are most at-risk themselves, other arguments included the uncertain long-term sequelae of COVID-19 and MIS-C. Proponents of mass-vaccination of children suggested that life with less concern over contracting or passing the infection would improve children's and adolescents' mental health and well-being, allowing them to resume education and social interactions important for their development. Also, it would prevent this age group from becoming a "pocket" of the population in which SARS-CoV-2 would continue to circulate freely and potentially mutate into more dangerous variants. However, at which exact point should children in high-income countries be prioritised for vaccination over vulnerable adults in LMICs remained a matter for serious ethical and logistical debate [48].

In parallel to this debate, vaccine trials in different age groups of minors were begun by the leading COVID-19 vaccine developers. This led to authorizations of COVID-19 Pfizer-BioNTech's mRNA BNT162b2 vaccines for the use among the adolescents aged 16-18 years, followed by 12-15 age group, and finally, 5-11 age group in Canada, the USA, and then Europe. On May 5, 2021, Canada was the first country to approve the COVID-19 vaccine for emergency use in children aged 12-15 years; later the same month, the FDA and European Medicines Agency also gave their approvals to the Pfizer-BioNTech COVID-19 vaccine for adolescents. Approvals for children 5-11 years old by the Food and Drug Administration (FDA) had followed on October 29, 2021. Several days earlier, an agency advisory committee reviewed data from a clinical trial that tested a low-dose version of the Pfizer-BioNTech vaccine in this age group and voted almost unanimously for recommending its emergency approval $[48,51]$.

These authorizations were based on a clear efficaciousness, immunogenicity and safety in children in those age groups [48,51] Double-blind, randomized, controlled, phase 1/2 clinical trials showed that the inactivated COVID-19 vaccine (CoronaVac) had good safety, tolerability, and immunogenicity in youths aged 3-17 years, inspiring the trials of other COVID-19 vaccines in minors of very early age. BNT162b2 vaccine has shown efficacy as high as 100\% in children aged 12-15 years against COVID-19 [51]. The CDC concluded that the benefits of vaccination outweigh the risks for COVID-19 vaccination in adolescents and young adults [98]. 
The European Academy of Paediatrics and the European Confederation for Primary Care Paediatricians [84] issued a joint statement on their position on vaccine implementation among minors. Their conclusion was that "action was necessary to clarify the future of SARS-CoV-2 vaccination in children and adolescents". This came after the American Academy of Pediatrics, the Advisory Committee on Immunization Practices and the Canadian Pediatric Society already advocated for the vaccination of all children and adolescents older than 12 years $[92,99,100]$, while the United Kingdom held back this decision because of a paucity of evidence about the safety and need of vaccination against SARS-CoV-2 in children [101].

The ECDC also took a position that, due to the limited benefits in children and adolescents, "careful consideration of the epidemiological situation and vaccine uptake in older age groups should be given before targeting children and adolescents" [102]. The European Pediatric Societies for Severe Acute Respiratory Syndrome Coronavirus 2 (SARS-CoV-2) Vaccination in Children group warned that a trial of AstraZeneca's COVID-19 vaccine in children aged 6-17 years was started in March 2021 in the UK, but it had to be paused as a precautionary measure because of reports of blood clots in adults. Therefore, European Pediatric Societies recommended against giving the vaccine to children younger than 12 years before "rigorous clinical trials are completed, adverse events carefully assessed, and not until vaccines are authorized and adequate dosage established by the respective national agencies", as this would ensure that vaccines were safe and effective for this age group [72]. With similar caution, vaccination was endorsed in principle as a positive and safe public health measure by the Expert Panel on Infectious Diseases and COVID-19 of the Global Pediatric Pulmonology Alliance (GPPA), as well as the number of relevant Chinese medical and pediatric authorities [79,83].

By July 2021, several countries have already made decisions to move ahead with vaccinating their children to curb the epidemic wave that was affecting them at the time. The most notable examples were Canada, Chile, China, Cuba, Israel, United Arab Emirates and USA. In Malta, close-knit family structures and adolescents having frequent contacts with their grandparents and travelling abroad for a school affected the decision. However, as mentioned earlier, vaccine advisers in the United Kingdom have recommended that only particularly vulnerable adolescents, or those living with vulnerable adults, should be vaccinated at that stage of the pandemic [57], which has changed later in 2021 when vaccination was offered to different age-groups of minors.

Some countries were quick to vaccinate children to try to avoid the further need for school closures. Relative to their risk of contracting the disease, children and adolescents have been disproportionately affected by lockdown measures. Within household outbreaks, children didn't seem responsible for the majority of household introductions of the virus. The impact of the reopening of schools on community transmission remained a matter of scientific debate. However, it was still difficult to justify why some countries prioritized the opening of retail and hospitality sectors while leaving their schools closed. Also, the cost of lower skills attainment would harm nations in the years to come, while protecting children from COVID-19 by closing schools has led to an increase of their hospitalizations due to accidents at home in some countries [2].

Because of uncertainty over the scientific evidence required to answer several important questions, it is clear that many professional societies preferred a cautious approach to advocating for mass vaccination among those younger than 18 years. Others argued that there was simply no time to wait for the perfect evidence and that it won't matter if it comes after most children have already been infected. One way of reasoning was to clearly explain that COVID-19 is a childhood illness, just as well as an illness of the adults. For example, only in the USA, millions of children have been infected with SARS-CoV-2 and at the end of October 2021, it was estimated that about 100000 children were being infected each week in the USA. As a result, tens of thousands of children have been hospitalized; about one-third did not have any pre-existing medical conditions. Almost 700 children have died from COVID-19 in the USA, while not a single child was reported to have died from vaccination by that time. Pfizer's mRNA vaccine was $90.7 \%$ effective against symptomatic COVID-19. Vaccineassociated myocarditis has in the main been a mild and self-limiting side-effect of vaccines, which is quite different from the cardiovascular problems that can be caused in children by COVID-19 or MIS-C [94]. So, essentially, it comes down to a question - between the two risks, which one should the carers choose? Although the risk posed by COVID-19 in children is very low, the vaccine still seems to be a much lesser risk, even without taking into account its other benefits [94].

\section{DISCUSSION ON CAREGIVERS' WILLINGNESS TO VACCINATE MINORS AND VACCINE HESITANCE AMONG THE ADOLESCENTS}

The work on ethical and legal aspects and the debate on the costs and benefits of vaccinating minors have led to another important area of research: using representative population-based surveys to establish caregivers' willingness to vaccinate minors and their vaccine hesitance [103-134]. In November 2020, one of the first 
such surveys was performed by the International COVID-19 Parental Attitude Study (COVIPAS) Group. At that point, $65 \%$ of caregivers intended to vaccinate their child against COVID-19 once a vaccine is available. The most common reason was to protect their child (62\%), while among the hesitant ones the most common reason was the vaccine's novelty (52\%) [103]. This early investigation was then followed by many further surveys that used similar methodology and explored this issue in different global settings. It emerged that $18 \%$ of parents would enrol their child in a clinical trial for a COVID-19 vaccine, while 14\% would agree to a randomized placebo-controlled study. Those parents were also more willing to be enrolled in a COVID-19 vaccine trial themselves, have an older child, have children who received all vaccinations according to schedule in their country, and have high school education or lower. Mothers were less likely to enrol their child in a trial than fathers [104].

In the US, in March 2021, 49\% of parents who had a child $\leq 12$ years of age had plans to vaccinate them when this became possible. Those with lower income and less education were more hesitant, quoting safety concerns and lack of need [118]. In New York City, in March and April 2021, 62\% of parents had plans to vaccinate their children under the age of 12 years, 15\% did not have such plans and 23\% were unsure [121]. These results were similar across the US because further representative studies also reported $46 \%-49 \%$ of parents willing to vaccinate their children, with vaccine side effects (62\%) and vaccine safety (49\%) being the most significant concerns affecting hesitancy $[115,117,123]$. The parents were more likely to vaccinate their children if they were older children, if parents had a bachelor's degree or higher education, if they received or were likely to receive the vaccine themselves, or if they voted for Democrats. The most trusted source of information was the child's doctor [123].

In China, parents' willingness to vaccinate their children was high from the start, at 70\%-87\% [105,120,122,133]. However, only $50 \%$ of parents with particularly vulnerable children were willing to have their child vaccinated [134]. The perception that a family member would support them in having their children take up COVID-19 vaccination was an important factor in their decision [105]. Caregivers who were male, aged 40-49 and from the rural area were more willing to vaccinate their children, while a history of adverse vaccine reactions and allergies in children led to hesitancy [120]. More than $80 \%$ of the caregivers expressed a high level of trust in vaccine information released by official and health-related agencies [120]. Several studies in China conducted at a later date in the pandemic found slightly different results $[114,124]$, where only $45 \%-53 \%$ would likely or very likely to have their children aged $<18$ years vaccinated. The issues were perceived vaccine efficacy, perceived protection duration, perceived likelihood that China would prevent another wave of COVID-19 outbreak with vaccines, and willingness to receive a COVID-19 vaccination themselves. In China, it seemed that information exposure through social media was associated with higher parental acceptability of COVID-19 vaccination while knowing anyone who had serious side effects following COVID-19 vaccination would deter them from vaccinating their children $[114,124]$.

The KUNO-Kids health study in Europe found that $58 \%$ of parents intended to get vaccinated against COVID-19 themselves, while 51\% intended to have their child vaccinated. Those willing typically also had stronger confidence in their knowledge on prevention measures and had beliefs that policy measures against COVID-19 were not exaggerated [110]. In Italy, $60 \%$ of the caregivers were inclined to vaccinate, while $30 \%$ were still considering this option and $10 \%$ were hesitant. Hesitancy rates were the highest in female caregivers under 30 years of age who had children aged 6-10 years, lower educational level, who relied on information found on the internet and social media, who disliked the idea of mandatory vaccination [108]. Among European adolescents, a history of allergies, migration background and female sex were associated with greater vaccine hesitancy $[126,127]$.

In a study in South Korea, $77 \%$ of parents intended to get vaccinated and $64 \%$ intended to have their children vaccinated, but only 50\% of children responded that they would get COVID-19 vaccination [125]. In Qatar, the parents of 12-year-old adolescents were more hesitant (22\%) compared to the 13-year-olds (16\%) and 15-year-olds (15\%). Moreover, parents of adolescents from Gulf countries (97\% Qatari) were more hesitant (35\%) as compared to the other nationalities. Also, parental vaccine hesitancy rates in Qatar were higher when adolescents suffered from chronic disease, or who were previously COVID-19 infected [128].

When asking US-based adolescents about their preferences, 65\%-76\% reported willingness to receive a COVID-19 vaccine [106,111], whereby about $40 \%$ were unconditionally prepared and about $30 \%$ were conditionally accepting if experts thought that vaccination was safe and helpful. They would trust the opinions of medical organizations such as Centres for Disease Control (CDC) and the World Health Organization (42\%) and health care professionals (32\%), while they were concerned about the side effects (36\%) and efficacy (20\%). There were ethnic differences, with Asian American adolescents being more, and African Americans less will- 
ing to get vaccinated than the rest [106]. Willingness also differed by physical health conditions, COVID-19 knowledge, practising physical distancing and adversity history [111]. In Chinese adolescents [119], the same proportion - 76\% - would accept COVID-19 vaccination. Those more likely to agree were younger adolescents who have heard about COVID-19 vaccines, thought that they could protect them from the infection, and believed that vaccines are safe. An interesting experiment showed that conveying strong social norms to young people led to reduced hesitancy and stronger intentions, but norms did not lead to different effects in comparison to standard vaccine information from the authorities. Moreover, young people were not more strongly influenced by norms when the reference group were other young people, rather than the society in general [113].

In England, 27910 students from 180 schools were asked about vaccine hesitancy between May and July 2021: $50 \%$ stated that they would take a vaccination, $37 \%$ were undecided, while $13 \%$ would opt-out. Younger students were considerably more hesitant, with 38\% of children aged $9,51 \%$ of those aged 13 and $78 \%$ of those aged 17 choosing to opt-in. Those hesitant would more likely belong to deprived socioeconomic contexts with higher rates of home rental vs homeownership, they were more likely to smoke or vape, use social media more, and feel that they did not belong in their school community more often. The study suggested that efforts to increase vaccination uptake may be necessary for these age groups [130]. Another study found that $42 \%$ of $9^{\text {th }}$ graders reported they are willing to get a COVID-19 vaccine, while $22 \%$ were "a little hesitant", 21\% were "somewhat hesitant", and 15\% were "very hesitant" [131]. In a Canadian survey, 63\% of parents intended to vaccinate their children against COVID-19. Those more hesitant were employed part-time, their children did not receive influenza vaccine, and they were more likely to believe that COVID-19 vaccination was unnecessary [132].

Among pediatricians and family physicians, changes were noted to routine childhood vaccination delivery as a result of the COVID-19 pandemic. In October-December 2020, for children aged 0-2 years, 5\% of pediatricians and $15 \%$ of family physicians reported they had stopped vaccinating these children at any time. For children aged $4-6$ years, $19 \%$ of pediatricians and $17 \%$ of family physicians reported stopping routine vaccinations at any time, and for children aged 11-18 years, the proportion was 24\% and 19\%, respectively. By 2021, nearly all of them returned to pre-pandemic vaccination services [107].

Some authors showed that there is a difference in endorsement of vaccines depending on the use of subjective or objective language. About 53\% of guardians in the US-based study endorsed vaccine administration for their children early in the pandemic when subjective language was used, but this proportion decreased to $46 \%$ later in the pandemic; however, when objective language was added, acceptance increased to $69 \%$. The most common reasons for hesitance were concerns about adverse effects and safety [129].

A study in Canada identified social inequalities in COVID-19 vaccine acceptance and uptake for children and adolescents, suggesting that special efforts will be required to reach underprivileged populations. Children from households with annual incomes <US\$100000 had an 18\% lower prevalence of being vaccinated, or being very likely to get vaccinated, compared to household incomes $\geq U S \$ 150000$. Moreover, vaccine-eligible adolescents from the most deprived neighbourhood were half as likely to be vaccinated compared to those from the least deprived neighbourhood [109].

\section{DISCUSSION ON VACCINE SAFETY AND EFFICACY TRIALS IN MINORS}

Based on previous research, the importance of including CYP in COVID-19 therapeutic trials was highlighted by numerous authors [135-168]. Their arguments were that waiting too long to enrol minors could deny them and their families the benefits of vaccination without a proper justification. It could also delay an effective response to the pandemic. However, it was also recognized that enrolling minors were also potentially associated with yet unknown risks. Soon after safety and immunogenicity were established in adults, vaccine trials in children and adolescents have also started [138].

One of the first published trials of vaccines in young people was on the safety and immunogenicity of the SARS-CoV-2 BNT162b1 mRNA vaccine in younger and older Chinese adults. It was a randomized, placebocontrolled, double-blind phase 1 study in a single-centre in Jiangsu province, China [141]. It was a parallelgroup, double-blind phase 1 trial of the vaccine candidate BNT162b1 in 144 healthy SARS-CoV-2-naive Chinese participants. The study concluded that BNT162b1 has an acceptable safety profile and produces high levels of humoral and T cell responses in an Asian population [141]. By the summer of 2021, the Chinese group of authors published a study on the safety, tolerability, and immunogenicity of an inactivated SARS-CoV-2 vaccine (CoronaVac) in healthy children and adolescents aged 3-17 years. It was a double-blind, randomized, controlled, phase 1/2 clinical trial at Hebei Provincial Center for Disease Control and Prevention in Zanhuang. The 
vaccine was given by intramuscular injection in two doses, spaced by four weeks. The primary safety endpoint was adverse reactions within four weeks after each shot, while the primary immunogenicity endpoint was the seroconversion rate of neutralizing antibody to live SARS-CoV-2 at 4 weeks after the second shot. Between Oct 31 and Dec 2, 2020, the authors enrolled 72 participants in phase 1, and between Dec 12 and Dec 30, 2020, they enrolled 480 participants were enrolled in phase 2 . In the combined safety profile of both phases, an adverse reaction occurred in 24\%-29\% of participants, with most adverse reactions being mild and moderate in severity. In phase 1, seroconversion of neutralizing antibody after the second dose was observed in $100 \%$ of participants, and phase 2 in 96.8\%-100\%. The authors concluded that CoronaVac was well tolerated and safe and induced humoral responses in children and adolescents aged 3-17 years and that the results support the use of 3.0 $\mathrm{\mu g}$ dose with a two-immunization schedule for further studies in children and adolescents [147].

In July 2021, the C4591001 Clinical Trial Group reported on the safety, immunogenicity, and efficacy of the Pfizer/BioNTech's BNT162b2 Covid-19 vaccine in adolescents. This was a multinational, placebo-controlled, observer-blinded trial. Participants received two injections of $30 \mu \mathrm{g}$ of BNT162b2 or placebo, 21 days apart, with an objective of noninferiority of the immune response to BNT162b2 in 12-15-year-old participants as compared with that in the 16-25 age group as an immunogenicity objective. Safety and efficacy against confirmed COVID-19 in the 12-15 age cohort were assessed. The study was based on 2260 adolescents who confirmed a favourable safety and side-effect profile - injection-site pain in $79 \%-86 \%$, fatigue in $60 \%-66 \%$, and headache in $55 \%-65 \%$; there were no vaccine-related serious adverse events. After dose 2 , the vaccine was not inferior in 12-15 age group participants relative to 16-25 age group participants, with a geometric mean ratio of neutralizing titers of $1.76(95 \%$ confidence interval $(\mathrm{CI})=1.47-2.10)$. The observed vaccine efficacy against infection was $100 \%$ (95\% CI=75\%-100\%). The study showed that the BNT162b2 vaccine in 12-to-15-yearold recipients produced a greater immune response than in young adults and was highly efficient against COVID-19 $[144,153,154]$. This study led to the authorization of the Pfizer/BioNTech COVID-19 vaccine for adolescents 12-15 years old in the USA [145,149] and Israel [146].

Towards the end of summer 2021, Moderna's mRNA-1273 SARS-CoV-2 vaccine was also evaluated in adolescents and the results were published. The authors used phase 2-3 placebo-controlled trial, randomly assigning healthy adolescents aged 12-17 years to receive two injections of the mRNA-1273 vaccine (100 $\mu \mathrm{g}$ in each) or placebo, with two shots given four weeks apart. The authors evaluated the safety and the non-inferiority of the immune response of mRNA-1273 in adolescents in comparison with young adults (18-25 years of age) in a phase 3 trial. Their secondary objectives were the efficacy of mRNA-1273 in preventing COVID-19 or asymptomatic SARS-CoV-2 infection. The study was based on 3732 participants. The most common adverse reaction was injection-site pain (in 92\%-93\%), headache (in 45\%-70\%), and fatigue (in 48\%-68\%). No serious adverse events were noted, with the geometric mean titer ratio of pseudovirus neutralizing antibody titers in adolescents relative to young adults of 1.08 (95\% CI=0.94-1.24). No cases of COVID-19 were recorded 14 days after the second shot among the vaccinated group [150,151]

Then, a group of Chinese authors reported on the safety and immunogenicity of an inactivated COVID-19 vaccine, BBIBP-CorV, in children and adolescents aged 3-17 years. The design was a randomized, double-blind, controlled, phase 1/2 trial, conducted at Shangqiu City Liangyuan District Center for Disease Control and Prevention in Henan, China. Children were categorized by age groups into 3-5 years, 6-12 years, and 13-17 years. They received three doses of $2 \mu \mathrm{g}, 4 \mu \mathrm{g}$, or $8 \mu \mathrm{g}$ of vaccine or control, 4 weeks apart. Between Aug and Sept 2020, 288 participants were randomly assigned to the vaccine or control group in phase 1, and 720 in phase 2. Adverse reactions were mild to moderate, with pain and fever arising in a minority of participants. BBIBPCorV also mounted robust humoral responses after two doses, supporting the use of a $4 \mu \mathrm{g}$ dose and two-shot regimen BBIBP-CorV in phase 3 trials in the population younger than 18 years [155].

Another Chinese study investigated the safety and immunogenicity of a recombinant adenovirus type-5-vectored COVID-19 vaccine with a homologous prime-boost regimen in healthy participants aged 6 years and above. It was a randomized, double-blind, placebo-controlled, phase $2 \mathrm{~b}$ trial. Participants received the low-dose vaccine, middle-dose vaccine or placebo. Prime-booster regimens were given intramuscularly 56 days apart. A total of 430 participants were enrolled, with 150 participants aged 6-17 years (so-called "MIN cohort"). A single dose in children and adolescents induced higher antibody responses than that elicited by two doses in adults, whereby homologous prime-boost vaccination was safe and tolerable. The authors concluded that the Ad5-vectored COVID-19 vaccine is safe and effective among children and adolescents and that a prime-boost regimen needs further exploration for the Ad5-vectored COVID-19 vaccine [156].

A systematic review of safety, immunogenicity, and efficacy of COVID-19 vaccines in children and adolescents published in September 2021 found eight published studies with a total of 2852 children and adolescents and 
28 ongoing clinical studies, but only two were randomized controlled trials, two were case series, and four were case reports. In all studies, the investigated COVID-19 vaccines had good safety profiles in children and adolescents, with injection site pain, fatigue, headache, and chest pain being the most common adverse events [162]. Of the 28 ongoing clinical studies, 23 were interventional studies, conducted in 15 countries. China had 10 ongoing trials, and the USA had 9, with BNT162b2 being the most commonly studied vaccine. The authors concluded that clinical studies of the COVID-19 vaccination in children and adolescents with longer follow-up time, larger sample size, and a greater variety of vaccines were still urgently needed [162].

In November 2021, the "C4591007 Clinical Trial Group" published their study which evaluated the BNT162b2 Covid-19 vaccine in children aged 5-11 years. This was a phase 1 , dose-finding study and an ongoing phase 2-3 randomized trial. The authors investigated the safety, immunogenicity, and efficacy of two doses of the BNT162b2 vaccine administered 21 days apart in children six months to 11 years of age. In phase 2-3 trial, participants were randomly assigned to receive two doses of either the BNT162b2 vaccine or placebo. Immune responses 4 weeks after the second dose were immunologically bridged to those in 16-25 age group, and vaccine efficacy against COVID-19 at 7 days or more after the second dose was assessed. A total of 48 children aged 5-11 years received $10 \mu \mathrm{g}, 20 \mu \mathrm{g}$, or $30 \mu \mathrm{g}$ of the BNT162b2 vaccine, 16 children at each dose level. Based on reactogenicity and immunogenicity, a dose level of $10 \mu \mathrm{g}$ was selected for the phase 2-3 trial. There, a total of 2268 children were randomly assigned to receive the BNT162b2 vaccine or placebo. The BNT162b2 vaccine had a favourable safety profile, with no vaccine-related serious adverse events noted. Four weeks after the second dose, the geometric mean ratio of severe acute respiratory syndrome coronavirus 2 (SARS-CoV-2) neutralizing titers in 5-to-11-year-olds to those in the 16-25 age group was 1.04, meeting the pre-specified immunogenicity success criterion which had the lower bound of two-sided 95\% CI>0.67, and geometric mean ratio point estimate $\geq 0.8$. Vaccine efficacy was $90.7 \%$ (95\% CI=67.7\%-98.3\%). The authors concluded that COVID-19 vaccination consisting of two 10- $\mu$ g doses of BNT162b2 administered 21 days apart was safe, immunogenic, and efficacious in children aged 5-11 years [164].

The first large mRNA vaccine trials in children and adolescents have shown that their results were excellent: Pfizer reported 100\% vaccine efficacy against COVID-19 in children aged 12 to 15 years [139] and 90.7\% in children aged 5 to 11 years [164]. These results influenced policy and decisions in many countries. At its October 2020 meeting, the Advisory Committee on Immunization Practices (ACIP) approved the 2021 Recommended Child and Adolescent Immunization Schedule for Ages 18 Years or Younger; weeks later, after Emergency Use Authorization of Pfizer-BioNTech COVID-19 vaccine by the FDA, ACIP issued an interim recommendation for use of Pfizer-BioNTech COVID-19 vaccine in persons aged $\geq 16$ years at its December 12 , 2020, meeting. In addition, ACIP approved an amendment to include COVID-19 vaccine recommendations in the child and adolescent immunization schedule. After the Emergency Use Authorization (EUA) of Moderna COVID-19 vaccine by the FDA, ACIP issued an interim recommendation for use of Moderna COVID-19 vaccine in persons aged $\geq 18$ years at its December 19, 2020, emergency meeting [140,142]. On May 10, 2021, FDA expanded the EUA for the Pfizer-BioNTech COVID-19 vaccine to include adolescents aged 12-15 years. On May 12, 2021, ACIP issued an interim recommendation for use of the Pfizer-BioNTech COVID-19 vaccine in adolescents aged 12-15 years for the prevention of COVID-19 [143].

\section{DISCUSSION ON VACCINE UPTAKE IN MINORS AND POPULATION-LEVEL EFFECTIVENESS}

Vaccines have been rapidly deployed in some high-income countries. By May 12, 2021, approximately 141.6 million doses of the Pfizer-BioNTech COVID-19 vaccine had been administered to persons aged $\geq 16$ years in the USA [140-143]. As of July 30, 2021, among the three COVID-19 vaccines authorized for use in the US, only the Pfizer-BioNTech BNT162b2 mRNA COVID-19 vaccine was authorized for adolescents aged 12-17 years. Beginning in June 2021, cases of myocarditis and myopericarditis (hereafter, myocarditis) after PfizerBioNTech vaccination were reported, primarily among young males after receipt of the second dose. On June 23, 2021, CDC's ACIP reviewed available data and concluded that the benefits of COVID-19 vaccination to individual persons and the population outweigh the risks for myocarditis.

As a result, ACIP recommended continued use of the vaccine in persons aged $\geq 12$ years. To further characterize the safety of the vaccine, adverse events after receipt of the Pfizer-BioNTech vaccine were reported to the Vaccine Adverse Event Reporting System (VAERS). Furthermore, adverse events and health impact assessments that were reported in v-safe (a smartphone-based safety surveillance system) were reviewed for US adolescents aged 12-17 years during December 14, 2020-July 16, 2021. As of July 16, 2021, approximately 8.9 million US 
adolescents aged 12-17 years had received the Pfizer-BioNTech vaccine. CDC and FDA continued to monitor vaccine safety and provide data to ACIP to guide COVID-19 vaccine recommendations [148].

On August 23, 2021, FDA approved a Biologics License Application for use of the Pfizer-BioNTech COVID-19 vaccine, Comirnaty (Pfizer, Inc.), in persons aged $\geq 16$ years. The ACIP COVID-19 Vaccines Work Group's conclusions regarding the evidence for the Pfizer-BioNTech COVID-19 vaccine were presented to ACIP at a public meeting on August 30, 2021. The additional information increased certainty that benefits from prevention of asymptomatic infection, COVID-19, and associated hospitalization and death outweighs vaccine-associated risks. On August 30, 2021, ACIP issued a recommendation for use of the Pfizer-BioNTech COVID-19 vaccine in persons aged $\geq 16$ years for the prevention of COVID-19 [157].

As of November 2, 2021, approximately 248 million doses of the Pfizer-BioNTech COVID-19 vaccine had been administered to persons aged $\geq 12$ years in the United States. On October 29, 2021, FDA issued a EUA amendment for a new formulation of the Pfizer-BioNTech COVID-19 vaccine for use in children aged 5-11 years, administered as 2 doses (10 $\mu \mathrm{g}, 0.2 \mathrm{~mL}$ each), 3 weeks apart. On November 2, 2021, the Advisory Committee on Immunization Practices (ACIP) issued an interim recommendation for use of the Pfizer-BioNTech COVID-19 vaccine in children aged 5-11 years for the prevention of COVID-19. The Pfizer-BioNTech COVID-19 vaccine showed high efficacy (>90\%) against COVID-19 in children aged 5-11 years [166].

Both Pfizer-BioNTech and Moderna vaccines are mRNA vaccines encoding the stabilized prefusion spike glycoprotein of the SARS-CoV-2 virus. Both mRNA vaccines were authorized and recommended as a 2-dose schedule, with second doses administered 21 days (Pfizer-BioNTech) or 28 days (Moderna) after the first dose. Besides those two vaccines, only a handful of others have been tested in young people over the age of 12, including two Chinese vaccines made by Sinovac and Sinopharm. Other studies are expected to report results in young people over the age of 12 soon, including the Zydus Cadila vaccine and the Covaxin inactivated coronavirus vaccine, both made in India. Thus far, the vaccines seem to be safe in adolescents, while companies have moved on to carrying out clinical trials in children as young as six months old $[57,166]$.

By July 31, 2021, 42.4\% of US adolescents aged 12-17 years received at least one dose of COVID-19 vaccine and $31.9 \%$ received both doses. The first dose coverage ranged from 20.2\% in Mississippi to $70.1 \%$ in Vermont, and the coverage was the highest in the age group $16-17$ years (50.6\%), followed by $14-15$ years ( $40.9 \%)$, and 12-13 (36.0\%) [152]. This uptake was based partly on the evidence that nearly one-third of adolescents aged 12-17 years who needed to be hospitalized with COVID-19 between March 2020 and April 2021 in the USA required intensive care, and about 5\% required endotracheal intubation and mechanical ventilation.

In Israel, the Pfizer-BioNTech BNT162b2 vaccine against SARS-CoV-2 was approved for use in adolescents in June 2021, shortly before an outbreak of the Delta variant. Short-term vaccine effectiveness against COVID-19 after the first dose was about 55\% and after the second dose about 90\% [158,160]. In the US, a randomized placebo-controlled trial demonstrated efficacy of the Pfizer-BioNTech vaccine of nearly $100 \%$ (95\% CI=75100) in preventing COVID-19 in children aged 12-15 years. In a test-negative, case-control study at 19 pediatric hospitals in 16 states during June 1-September 30, 2021, the effectiveness of two doses against COVID-19 hospitalization was assessed among those aged 12-18years. A total of 464 hospitalized persons were included in the study, 179 case-patients and 285 controls, with a median age of 15 years. Among them, $72 \%$ had at least one underlying condition, including obesity, and $68 \%$ attended in-person school. Similarly to the observations in Israel, effectiveness of two doses was 93\% (95\% CI=83-97) during the Delta period [161,168].

The next set of data that will be awaited is the information on vaccine roll-out among the age group 5-11 years. The administration of the vaccine in this age group began in early November 2021 [163,165], and the expectation is that the Pfizer-BioNTech vaccine will provide $90 \%$ protection against infection in this age group of children [167].

In Israel, the effectiveness of Pfizer-BioNTech BNT162b2 vaccine against documented SARS-CoV-2 infection among adolescents aged 12-18 years was studied among 184905 vaccinated adolescents. A total of 94354 vaccine recipients were matched with 94354 unvaccinated controls and the frequency of polymerase-chain-reaction (PCR) testing for SARS-CoV-2 was similar in the vaccinated and unvaccinated populations. The estimated vaccine effectiveness was 59\% (95\% CI=52-65) on days $14-20$ after the first dose, $66 \%$ (95\% CI=59-72) on days 21-27 after the first dose, and 90\% (95\% CI=88-92) on days 7-21 after the second dose. The estimated vaccine effectiveness against symptomatic COVID-19 was $57 \%(95 \% \mathrm{CI}=39-71)$ on days $14-20$ after the first dose, $82 \%$ (95\% CI $=73-91)$ on days $21-27$ after the first dose, and $93 \%(95 \% \mathrm{CI}=88-97)$ on days $7-21$ after the second dose. This study showed that the BNT162b2 mRNA vaccine was highly effective in the first few weeks after vaccination against both documented infection and symptomatic COVID-19 with the Delta variant among adolescents between the ages of 12-18 years [169]. 


\section{DISCUSSION ON POSSIBLE SIDE EFFECTS OF COVID-19 VACCINES IN CHILDREN AND YOUNG PEOPLE}

The literature on the possible side effects of COVID-19 vaccines in children and young people is still sparse [170-190]. First reports appeared in the second half of 2021. A case series on adolescents receiving the PfizerBioNTech BNT162b2 mRNA COVID-19 vaccine from 3 pediatric medical centres in Israel [170] described seven males who were 16-18 years old, of Jewish descent, with chest pain that began 1-3 days following vaccination. In six of the seven patients, symptoms began after the second dose, and in one patient they followed the first dose. All cases were mild and didn't require specific support, either cardiovascular or respiratory. A comparison with previous years showed that the incidence of myocarditis during the vaccination period was elevated. Seven further cases of acute myocarditis or myocarditis in healthy male adolescents from the USA showed a very similar picture: chest pain within four days after the second dose of Pfizer-BioNTech COVID-19 vaccination in all cases, where five also had a fever. COVID-19 was ruled out by PCR and MIS-C by detailed clinical assessment. Six also had negative SARS-CoV-2 antibody assays, suggesting no previous infection with SARS-CoV-2, and all seven had an elevated troponin. On cardiac MRI, they presented late gadolinium enhancement, characteristic of myocarditis. All seven patients rapidly recovered. In three, non-steroidal antiinflammatory drugs were used, while four received intravenous immunoglobulin and corticosteroids [171].

Further reports supported this initial observation, with remarkably similar features. Five male patients in Israel with a median age of 23 had post- BNT162b2 vaccine myocarditis [172], and eight further adolescents in the USA presented with myocarditis within 4 four days of receiving a dose of BNT162b2 vaccine [175]. A series of 25 children, aged 12-18 years, were diagnosed with probable myocarditis after COVID-19 mRNA vaccination at eight US centres between May and June 2021. Again, in 88\%, the cases followed the second dose of vaccine, and chest pain was the most common presenting symptom in them all - after a median of 2 days (range from $<1$ to 20 days) following vaccination. All affected children had an elevated plasma troponin concentration, 92\% showed normal cardiac function, and 94\% had late gadolinium enhancement. Most were treated with ibuprofen or an equivalent nonsteroidal anti-inflammatory drug and everyone was well within a week [177].

Another case series of 15 minors with myocarditis from a single institution in the US [179] showed that 14 were males with a median age of 15 years (range: $12-18$ years). Their symptoms started 1-6 days after vaccination and included chest pain in all patients, fever in $67 \%$, myalgia in $53 \%$, and headache in $40 \%$, with troponin levels elevated in all patients at admission. Decreased left ventricular ejection fraction was present in 20\% and abnormal global strain in 33\%. Late gadolinium enhancement was seen in $80 \%$ of patients. No patient required intensive care unit (ICU) admission and the median hospital length of stay was two days (range 1-5). Only one patient had persistent borderline low left ventricular systolic function on echocardiogram, with an ejection fraction of 54\%, after 14 days of follow-up [179]. Then, two further cases of a similar presentation were reported [185], but a larger case series was needed.

In a retrospective multicenter study across 16 US hospitals, in patients $<21$ years of age, the acronym C-VAM was introduced for "coronavirus disease 2019 vaccination-associated myocarditis" and a series of 63 patients with a mean age of 15.6 years was presented [180]. Again, 92\% were male and all of them but one presented C-VAM after the second dose. Only four patients had significant dysrhythmia; 14\% had mild left ventricular dysfunction on echocardiography, and 88\% met the diagnostic CMR Lake Louise criteria for myocarditis. Late gadolinium enhancement on CMR was more prevalent in comparison with MIS-C. No one required ICU support and there were no deaths. After about a month of follow-up, the symptoms, arrhythmias, and ventricular dysfunction resolved. Still, a long-term follow-up will be needed to document any persisting consequences. Mechanisms of these myocardial tissue changes also need to be understood [180].

By May 31, 2021, early reports of myocarditis prompted the Israeli Ministry of Health to initiate active surveillance. They analyzed the occurrence of myocarditis by computing the risk difference for the comparison of the incidence after the first and second vaccine doses, which were given 21 days apart, and by calculating the standardized incidence ratio of the observed-to-expected incidence. They found 304 persons with symptoms of myocarditis, but 21 were reclassified; of the remaining 283 cases, 142 occurred after the Pfizer-BioNTech BNT162b2 vaccination, and 136 diagnoses were either definitive or probable. In 95\% of cases, the clinical presentation was mild, but one fulminant case was fatal. The overall risk difference between the first and the second dose was 1.76 per 100000 persons, with the largest risk among males aged 16-19 years (13.73 per 100000 persons). As compared to historical incidence data, the standardized incidence ratio was 5.34. It was the highest after the second dose in males aged 16-19 years (13.60). When fully vaccinated recipients were compared to unvaccinated, their increased risk was 2.35 , but the rate ratio was the highest in males aged 1619 years whose absolute risk was about 1 in 6500 [186]. 
After reports of myocarditis and pericarditis in mRNA vaccine recipients, which predominantly occurred in young males after the second dose, a US Advisory Committee on Immunization Practices (ACIP) meeting was rapidly convened to review reported cases of myocarditis and pericarditis and discuss the benefits and risks of mRNA COVID-19 vaccination in the US. On June 23, 2021, after reviewing available evidence including that for risks of myocarditis, ACIP determined that the benefits of using mRNA COVID-19 vaccines under the FDA's Emergency Use Authorizations (EUA) outweigh the risks in adolescents and young adults. The EUA has been modified to include information on myocarditis after receipt of mRNA COVID-19 vaccines, with the fact sheets to be provided before vaccination; in addition, CDC has developed patient and provider education materials about the possibility of myocarditis and symptoms of concern, to ensure prompt recognition and management of myocarditis $[173,176]$. Importantly, none of the patients fulfilled the criteria for MIS-C or Kawasaki-like disease and there was no evidence of acute SARS-CoV-2 infection [184].

By mid-July 2021, the CDC's VAERS in the US collected 9246 reports of post-vaccination adverse events among the adolescents aged 12-17 years or about 1 per 1000 vaccinated. More than 90\% of those reports were not for serious symptoms and they involved dizziness, fainting, nausea, headache, and fever. A total of 863 events were considered serious, including chest pain, increased troponin levels, and myocarditis. Myocarditis disproportionately affected males and it was reported in 397 cases, representing $4.3 \%$ of all VAERS reports. Fourteen deaths were also reported, but there was no apparent pattern that would indicate that vaccination was the cause, although the cause of death for 6 adolescents was "unknown or pending". About half of the recipients of the Pfizer-BioNTech's mRNA vaccine, the only one licensed for this age group at the time, reported systemic reactions after the first dose, and about two-thirds after the second dose. They usually occurred during the first day after vaccination. The reported symptoms included injection site pain, fatigue, headache, and muscle pain. Fever was present in about one-third of the week after the second dose, while about one-quarter were unable to perform daily activities the day after their second shot [183]

Another country that was quick to report the side effects of the COVID-19 Pfizer-BioNTech mRNA vaccine in children aged 12-18 years was Saudi Arabia. An internet-based study using a self-administered online survey was prone to self-selection bias and it reported at least one side effect in $60 \%$ of participants. Among them, $90 \%$ reported pain or redness at the site of injection (90\%), 67\% fatigue, 59\% fever, 55\% headache, $21 \%$ nausea or vomiting, and $20 \%$ chest pain and shortness of breath, with only $2 \%$ reporting joint or bone pain [189]. Meanwhile in Scandinavia, Sweden, Norway, and Finland suspended the use of the Moderna vaccine in young people "as a precaution" on October 7, 2021, after reports of possible rare side effects. This applied to anyone born in 1991 or later. In Norway, the use of Moderna's vaccine was suspended in those under 18 years of age, who were offered the Pfizer-BioNTech BNT162b2 vaccine instead. The causes of this decision were the reports of an increased risk of myocarditis and pericarditis, which seemed to occur more often after the Moderna vaccine than Pfizer-BioNTech BNT162b2 [187].

In addition to myocarditis, other very rare side effects of vaccination underwent scrutiny. Cerebral venous thrombosis has been studied in adults through a multicentre cohort study in the UK, but its surveillance should be extended to minors, too. In the adults, the new syndrome was termed "vaccine-induced immune thrombotic thrombocytopenia" (VITT), with cerebral venous thrombosis being the most common manifestation. Between April 1 and May 20, 2021, the authors received data on 99 patients from collaborators in 43 hospitals across the UK, with 70 eventually having the VITT confirmed. The primary outcome, which was defined as "death or dependency", occurred more frequently in patients with VITT-associated cerebral venous thrombosis - in 33 of 70 patients. Non-heparin anticoagulants and intravenous immunoglobulin showed some effectiveness against these outcomes [178]. Opinions were expressed that children can also have thrombosis with COVID-19 and that this potential problem should be closely monitored [174].

In Japan, a case of new-onset pediatric nephrotic syndrome following Pfizer-BioNTech BNT162b2 vaccination was described. Several adult cases of minimal change nephrotic syndrome have already been reported earlier after the vaccine, but no warnings were published about children. A 15-year-old boy had no underlying diseases and he developed eyelid edema four days after vaccination, with peripheral oedema of the lower extremities four days later. Treatment involved $60 \mathrm{mg}$ of oral daily prednisolone, and complete remission was achieved within 12 days with no residual complications (eg, hypertension or acute kidney injury) [188] .

It has also been proposed in adults that MIS may occur after SARS-CoV-2 vaccination, which is then no longer branded as "MIS-C", but rather as "MIS-V". A multisystem inflammatory syndrome was reported in an 18-year-old adolescent after the SARS-CoV-2 vaccine from Pfizer-BioNTech BNT162b2. The key clinical features were fever for three consecutive days, pericardial effusion, elevated CRP/NT-BNP/Troponin T/D-dimers, cardiac involvement, and positive SARS-CoV-2 antibodies. The disease started 10 weeks after the second dose 
of the vaccine. A pericardial effusion was diagnosed by echocardiography, with the CRP, NT-BNP, D-dimers and troponin T levels all elevated [190].

In the initial study of the safety and tolerability of the Pfizer-BioNTech BNT162b2 vaccine in extremely vulnerable children aged 12-15 years, eight events were reported in six children after the first dose, and they all resolved within less than three days. Those were mild rash, headache, diarrhoea, presumed sore throat, neck pain, difficulty sleeping and decreased levels of blood glucoses. After the second dose, eight additional events occurred among five children: diarrhoea, vomiting, armpit swelling, and blisters around the mouth, which were not thought to be related to vaccination [182]. In another study, that looked into the safety of the administration of Pfizer-BioNTech BNT162b2 vaccine in youth and young adults with a history of acute lymphoblastic leukaemia (ALL) and allergy to polyethene glycol (PEG)-asparaginase, the fact that the mRNA vaccines contain PEG as a stabilizer was specifically considered. Most patients treated with contemporary combination treatments for ALL receive PEG-asparaginase (PEG-ASNase), but 10\%-30\% develop allergic reactions. The authors concluded that optimizing access and safety for vaccine administration for these patients is critical and described a process developed to support vaccination among young people with a history of PEG-ASNase allergy [181].

\section{CONCLUSIONS}

Research to characterize SARS-CoV-2 infection and COVID-19 in CYP rapidly evolved during 2020 and 2021 and led to recommendations from several professional societies and authorizing bodies that vaccinating CYP should be safe and effectively protect them from COVID-19. Ethical and legal aspects of vaccinating minors were debated, leading to a vivid discussion in the scientific literature over the arguments whether children and young people should also be included in COVID-19 vaccine trials. The emergence of new variants of SARS-CoV-2 which had increased transmissibility added another argument to the debate as it became clear that very high population-based vaccination coverage would be required to control the pandemic. A body of literature then explored caregivers' willingness to vaccinate minors and the extent of vaccine hesitancy that could meet national programmes of vaccinating children and young people. Eventually, vaccines were approved for those aged 16-18 years; then, the first vaccine safety and efficacy trials were conducted in the adolescents aged 12-15 years; and finally, children under the age of 12 were also included. Population-level effectiveness of this vaccination was then determined, and possible side effects such as myocarditis were documented and discussed. However, the debate on the benefits will continue given likely rapidly waning immunity in CYP, which was reported in several papers both in our first and the second editorial on CYP; the emergence of the new variants of the SARS-CoV-2; and the proposals in some countries of making COVID-19 vaccines mandatory among minors.

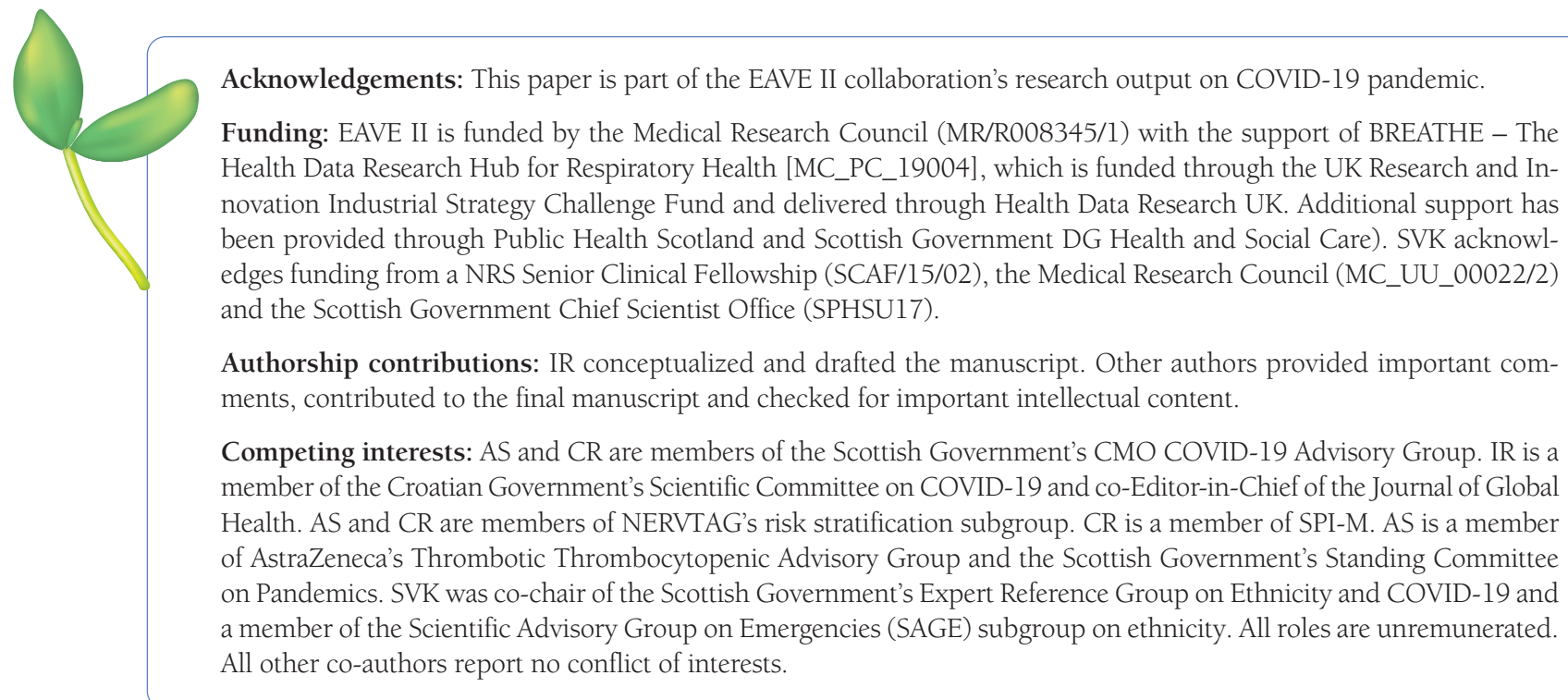


1 Rudan I. Evaluating different national strategies to contain the COVID-19 pandemic before mass vaccination. J Glob Health. 2021;11:01004. Medline:34055322 doi:10.7189/jogh.11.01004

2 Snape MD, Viner RM. COVID-19 in children and young people. Science. 2020;370:286-8. Medline:32958582 doi:10.1126/ science.abd6165

3 Reiss DR, Caplan AL. Considerations in mandating a new Covid-19 vaccine in the USA for children and adults. J Law Biosci. 2020;7:Isaa025. Medline:32728468 doi:10.1093/jlb/lsaa025

4 Giubilini A, Savulescu J, Wilkinson D. COVID-19 vaccine: vaccinate the young to protect the old? J Law Biosci. 2020;7:lsaa050. Medline:32959006 doi:10.1093/jlb/lsaa050

5 Bell BP, Romero JR, Lee GM. Scientific and Ethical Principles Underlying Recommendations From the Advisory Committee on Immunization Practices for COVID-19 Vaccination Implementation. JAMA. 2020;324:2025-6. Medline:33090194 doi:10.1001/jama.2020.20847

6 Savulescu J, Giubilini A, Danchin M. Global Ethical Considerations Regarding Mandatory Vaccination in Children. J Pediatr. 2021;231:10-6. Medline:33484698 doi:10.1016/j.jpeds.2021.01.021

7 Cooper DM, Afghani B, Byington CL, Cunningham CK, Golub S, Lu KD, et al. SARS-CoV-2 vaccine testing and trials in the pediatric population: biologic, ethical, research, and implementation challenges. Pediatr Res. 2021;90:966-70. Medline:33627824 doi:10.1038/s41390-021-01402-z

8 Coyne-Beasley T, Hill SV, Zimet G, Kanbur N, Kimberlin D, Raymond-Flesch M, et al. COVID-19 Vaccination of Adolescents and Young Adults of Color: Viewing Acceptance and Uptake With a Health Equity Lens. J Adolesc Health. 2021;68:844-6. Medline:33814282 doi:10.1016/j.jadohealth.2021.02.008

9 Matsui K, Inoue Y, Yamamoto K. SARS-CoV-2 Human Challenge Trials: Rethinking the Recruitment of Healthy Young Adults First. Ethics Hum Res. 2021;43:37-41. Medline:33821569 doi:10.1002/eahr.500089

10 de Miguel Beriain I. We should not vaccinate the young to protect the old: a response to Giubilini, Savulescu, and Wilkinson. J Law Biosci. 2021;8:lsab015. Medline:34040784 doi:10.1093/jlb/lsab015

11 Brusa M, Barilan YM. Voluntary COVID-19 vaccination of children: a social responsibility. J Med Ethics. 2021;47:543-6. Medline:34117126 doi:10.1136/medethics-2021-107370

12 Giubilini A, Gupta S, Heneghan C. A focused protection vaccination strategy: why we should not target children with COVID-19 vaccination policies. J Med Ethics. 2021;47:565-6. Medline:34233955 doi:10.1136/medethics-2021-107700

13 Morgan L, Schwartz JL, Sisti DA. COVID-19 Vaccination of Minors Without Parental Consent: Respecting Emerging Autonomy and Advancing Public Health. JAMA Pediatr. 2021;175:995-6. Medline:34251411 doi:10.1001/jamapediatrics.2021.1855

14 Olick RS, Yang YT, Shaw J. Adolescent Consent to COVID-19 Vaccination: The Need for Law Reform. Public Health Rep. 2022. Epub ahead of print. Medline:34546811 doi:10.1177/00333549211048784

15 Wilkinson D, McBride AKS. Clinical ethics: consent for vaccination in children. Arch Dis Child. 2022. Epub ahead of print. Medline:34580058 doi:10.1136/archdischild-2021-322981

16 Majeed A, Hodes S, Marks S. Consent for covid-19 vaccination in children. BMJ. 2021;374. Medline:34584000

17 Lanphier E, Fyfe S. Pediatric Off-Label Use of Covid-19 Vaccines: Ethical and Legal Considerations. Hastings Cent Rep. 2021. Epub ahead of print. Medline:34750807 doi:10.1002/hast.1296

18 Velavan TP, Pollard AJ, Kremsner PG. Herd immunity and vaccination of children for COVID-19. Int J Infect Dis. 2020;98:145. Medline:32585285 doi:10.1016/j.ijid.2020.06.065

19 Rosenthal CM, Thompson LA. Opting Out of Vaccines for Your Child. JAMA Pediatr. 2020;174:916. Medline:32716493 doi:10.1001/jamapediatrics.2020.2475

20 Opel DJ, Diekema DS, Ross LF. Should We Mandate a COVID-19 Vaccine for Children? JAMA Pediatr. 2021;175:125-6. Medline:32926083 doi:10.1001/jamapediatrics.2020.3019

21 Anderson EJ, Campbell JD, Creech CB, Frenck R, Kamidani S, Munoz FM, et al. Warp Speed for Coronavirus Disease 2019 (COVID-19) Vaccines: Why Are Children Stuck in Neutral? Clin Infect Dis. 2021;73:336-40. Medline:32945335 doi:10.1093/cid/ciaal425

22 Eberhardt CS, Siegrist CA. Is there a role for childhood vaccination against COVID-19? Pediatr Allergy Immunol. 2021;32:916. Medline:33113210 doi:10.1111/pai.13401

23 Zimet GD, Silverman RD, Fortenberry JD. Coronavirus Disease 2019 and Vaccination of Children and Adolescents: Prospects and Challenges. J Pediatr. 2021;231:254-8. Medline:33161025 doi:10.1016/j.jpeds.2020.11.002

24 Olorunsaiye CZ, Yusuf KK, Reinhart K, Salihu HM. COVID-19 and Child Vaccination: A Systematic Approach to Closing the Immunization Gap. Int J MCH AIDS. 2020;9:381-5. Medline:33014624 doi:10.21106/ijma.401

25 Kamidani S, Rostad CA, Anderson EJ. COVID-19 vaccine development: a pediatric perspective. Curr Opin Pediatr. 2021;33:144-51. Medline:33278108 doi:10.1097/MOP.0000000000000978

26 Goldschmidt K. COVID-19 Vaccines for Children: The Essential Role of the Pediatric Nurse. J Pediatr Nurs. 2021;57:96-8. Medline:33342640 doi:10.1016/j.pedn.2020.12.004

27 Wong BLH, Ramsay ME, Ladhani SN. Should children be vaccinated against COVID-19 now? Arch Dis Child. 2021. Epub ahead of print. Medline:33402324 doi:10.1136/archdischild-2020-321225

28 Dal-Ré R. Mandatory Coronavirus Disease 2019 Vaccine for Children? JAMA Pediatr. 2021;175:533-4. Medline:33555291 doi:10.1001/jamapediatrics.2020.6010

29 Opel DJ, Diekema DS, Ross LF. Mandatory Coronavirus Disease 2019 Vaccine for Children?. JAMA Pediatr. 2021;175:534. Medline:33555288 doi:10.1001/jamapediatrics.2020.6013 
30 Eberhardt CS, Siegrist CA. Do we need a pediatric COVID-19 vaccine? Rev Med Suisse. 2021;17:353-357. French. Medline:33599412

31 Klass P, Ratner AJ. Vaccinating Children against Covid-19 - The Lessons of Measles. N Engl J Med. 2021;384:589-91. Published online Jan 20, 2021. Medline:33471977 doi:10.1056/NEJMp2034765

32 Kao CM, Orenstein WA, Anderson EJ. The Importance of Advancing Severe Acute Respiratory Syndrome Coronavirus 2 Vaccines in Children. Clin Infect Dis. 2021;72:515-8. Medline:33527122 doi:10.1093/cid/ciaa712

33 Principi N, Esposito S. Why It Is Important to Develop an Effective and Safe Pediatric COVID-19 Vaccine. Vaccines (Basel). 2021;9:127. Medline:33562619 doi:10.3390/vaccines9020127

34 Bhopal SS, Absoud M. Vaccinating children to prevent long covid? More caution is needed in interpreting current epidemiological data. BMJ. 2021;372. Medline:33627337 doi:10.1136/bmj.n520

35 Plotkin SA, Levy O. Considering Mandatory Vaccination of Children for COVID-19. Pediatrics. 2021;147:e2021050531. Published online Mar 11, 2021. Medline:33707197 doi:10.1542/peds.2021-050531

36 Caselli D, Aricò M. SARS-CoV-2 Vaccination for Children-An Open Issue. Pediatr Rep. 2021;13:95-7. Medline:33668173 doi:10.3390/pediatric13010013

37 Thomson H. Covid-19 vaccines for kids. New Sci. 2021;250:8-9. Published online Apr 9, 2021. Medline:33867618 doi:10.1016/ S0262-4079(21)00582-0

38 Obaro S. COVID-19 herd immunity by immunisation: are children in the herd? Lancet Infect Dis. 2021;21:758-9. Published online Apr 19, 2021. Medline:33887207 doi:10.1016/S1473-3099(21)00212-7

39 Duong D. Should Canada's approach to COVID-19 and kids change with new variants? CMAJ. 2021;193:E623-4. Medline:33903136 doi:10.1503/cmaj.1095936

40 Anderson EJ, Kamidani S, Orenstein W, Campbell JD. COVID-19 Vaccines Have Moved Out of Neutral, but Still Gearing Up in Children. Clin Infect Dis. 2021. Epub ahead of print. Medline:33949653

41 Committee on Infectious Diseases. COVID-19 Vaccines in Children and Adolescents. Pediatrics. 2021;148:e2021052336. Published online May 12, 2021. Medline:33980697 doi:10.1542/peds.2021-052336

42 Lavine JS, Bjornstad O, Antia R. Vaccinating children against SARS-CoV-2. BMJ. 2021;373. Medline:33985969

43 Moghadas SM, Fitzpatrick MC, Shoukat A, Zhang K, Galvani AP. Simulated Identification of Silent COVID-19 Infections Among Children and Estimated Future Infection Rates With Vaccination. JAMA Netw Open. 2021;4:e217097. Medline:33890990 doi:10.1001/jamanetworkopen.2021.7097

44 Nuzhath T, Ajayi KV, Fan Q, Hotez P, Colwell B, Callaghan T, et al. Childhood immunization during the COVID-19 pandemic in Texas. Vaccine. 2021;39:3333-7. Published online Apr 27, 2021. Medline:34020814 doi:10.1016/j.vaccine.2021.04.050

45 Wilson E, Girotto J, Passerrello N, Stoffella S, Shah D, Wu A, et al. Importance of Pediatric Studies in SARS-CoV-2 Vaccine Development. J Pediatr Pharmacol Ther. 2021;26:418-21. Medline:34035689 doi:10.5863/1551-6776-26.4.418

46 Thompson LA, Rasmussen SA. Children and COVID-19 Vaccines. JAMA Pediatr. 2021. Epub ahead of print. Medline:34086047 doi:10.1001/jamapediatrics.2021.1974

47 Gostin LO, Shaw J, Salmon DA. Mandatory SARS-CoV-2 Vaccinations in K-12 Schools, Colleges/Universities, and Businesses. JAMA. 2021;326:25-6. Medline:34096972 doi:10.1001/jama.2021.9342

48 The Lancet Infectious Diseases. Should we vaccinate children against SARS-CoV-2? Lancet Infect Dis. 2021;21:889.. Medline:34119070 doi:10.1016/S1473-3099(21)00339-X

49 Abi-Jaoude E. Vaccinating children against SARS-CoV-2: maximise uptake among adults while prioritising the most vulnerable. BMJ. 2021;373. Medline:34135097 doi:10.1136/bmj.n1533

50 Kang HM, Choi EH, Kim YJ. Updates on the coronavirus disease 2019 vaccine and consideration in children. Clin Exp Pediatr. 2021;64:328-38. Medline:34148333 doi:10.3345/cep.2021.00696

51 Zou X, Cao B. COVID-19 vaccines for children younger than 12 years: are we ready? Lancet Infect Dis. 2021 Jun 28:S14733099(21)00384-4. Epub ahead of print. PMID: 34197765; PMCID: PMC8238447.

52 Li G, Finn A, Pollard AJ. Should we be vaccinating children against COVID-19 in high-income countries? Expert Rev Vaccines. 2021;20:1043-6. Medline:34224291 doi:10.1080/14760584.2021.1951245

53 Gurdasani D, Drury J, Greenhalgh T, Griffin S, Haque Z, Hyde Z, et al. Mass infection is not an option: we must do more to protect our young. Lancet. 2021;398:297-8. Medline:34245669 doi:10.1016/S0140-6736(21)01589-0

54 Wilkinson D, Finlay I, Pollard AJ, Forsberg L, Skelton A. Should we delay covid-19 vaccination in children? BMJ. 2021;374:n1687. Medline:34244181 doi:10.1136/bmj.n1687

55 Praticò AD, Ruggieri M. COVID-19 vaccination for children: may be necessary for the full eradication of the disease. Pediatr Res. 2021;90:1102-3. Medline:34253861 doi:10.1038/s41390-021-01643-y

56 Cauchemez S, Bosetti P, Kiem CT, Mouro V, Consoli A, Fontanet A. Education and mental health: good reasons to vaccinate children. Lancet. 2021;398:387. Medline:34273293 doi:10.1016/S0140-6736(21)01453-7

57 Ledford H. Should children get COVID vaccines? What the science says. Nature. 2021;595:638-9. Medline:34285402 doi:10.1038/d41586-021-01898-9

58 Saxena S, Skirrow H, Wighton K. Should the UK vaccinate children and adolescents against covid-19? BMJ. 2021;374:n1866. Medline:34301635 doi:10.1136/bmj.n1866

59 Ladhani SN. Crossing the Rubicon: A fine line between waiting and vaccinating adolescents against COVID-19. J Infect. 2021;83:294-7. Medline:34302866 doi:10.1016/j.jinf.2021.07.015

60 Wilson C. Is it time to vaccinate children? New Sci. 2021;251:8-9. Medline:34305249 
61 Kampmann B, Okomo U. COVID-19 vaccines for children in LMICs: another equity issue. Lancet. 2021;398:731-2. Medline:34339625 doi:10.1016/S0140-6736(21)01748-7

62 Schleiss MR, John CC, Permar SR. Children are the key to the Endgame: A case for routine pediatric COVID vaccination. Vaccine. 2021;39:5333-6. Medline:34393021 doi:10.1016/j.vaccine.2021.08.005

63 Marchetti F, Tamburlini G. Other good reasons for covid-19 vaccination in pre-adolescent and adolescent populations. BMJ. 2021;374. Medline:34417166 doi:10.1136/bmj.n2052

64 Merry S. Editorial: Are our kids getting a fair deal? Child Adolesc Ment Health. 2021;26:193-4. Medline:34459536 doi:10.1111/ camh. 12498

65 Bonati M, Benelli E. Vaccinating adolescents wisely against COVID-19. BMJ Paediatr Open. 2021;5:e001191. Medline:34493988

66 de Beer PAM, Van den Abbeele K. Inviting adolescents aged 12-17 for covid-19 vaccination: the need for patience. BMJ. 2021;374. Medline:34503968 doi:10.1136/bmj.n2172

67 Iacobucci G. Covid-19: Children aged 12-15 should be offered vaccine, say UK's chief medical officers. BMJ. 2021;374. Medline:34518163 doi:10.1136/bmj.n2248

68 Iacobucci G. Covid-19: Vaccinating children will help end pandemic, says minister. BMJ. 2021;374. Medline:34521631 doi:10.1136/bmj.n2254

69 Gimma A, Lal S. Considerations for mitigating COVID-19 related risks in schools. Lancet Reg Health Am. 2021;2:100077. Medline:34522913 doi:10.1016/j.lana.2021.100077

70 Ioannidis JPA. COVID-19 vaccination in children and university students. Eur J Clin Invest. 2021;51:e13678. Medline:34529274 doi:10.1111/eci.13678

71 Kobayashi J, Takeuchi R, Shibuya F, Murata Y, Takahashi K. Recommendations for the urgent need to vaccinate school-aged and adolescent children against COVID-19 in the Asia-Pacific region. Trop Med Health. 2021;49:74. Medline:34530919 doi:10.1186/s41182-021-00365-5

72 Pettoello-Mantovani M, Carrasco-Sanz A, Huss G, Mestrovic J, Vural M, Pop TL, et al. Viewpoint of the European Pediatric Societies over Severe Acute Respiratory Syndrome Coronavirus 2 (SARS-CoV-2) Vaccination in Children Younger Than Age 12 Years Amid Return to School and the Surging Virus Variants. J Pediatr. 2021. Epub ahead of print. Medline:34536493 doi:10.1016/j.jpeds.2021.09.013

73 Gupta S, Smith L, Diakiw A. Avoidance of COVID-19 for Children and Adolescents and Isolation Precautions. Pediatr Clin North Am. 2021;68:1103-18. Medline:34538302 doi:10.1016/j.pcl.2021.05.011

74 Kostoff RN, Calina D, Kanduc D, Briggs MB, Vlachoyiannopoulos P, Svistunov AA, et al. Why are we vaccinating children against COVID-19? Toxicol Rep. 2021;8:1665-84. Medline:34540594 doi:10.1016/j.toxrep.2021.08.010

75 Saxena S, Skirrow H, Bedford H, Wighton K. Covid-19 vaccines for teenagers: conversations and consent. BMJ. 2021;374. Medline:34551892 doi:10.1136/bmj.n2312

76 Liu F, Fu HD, Mao JH. Coronavirus disease 2019 vaccine for children in China: when to start? Mandatory or voluntary? Chin Med J (Engl). 2021. Epub ahead of print. Medline:34561329 doi:10.1097/CM9.0000000000001779

77 Bird PW, Riff R, Folwell A, Holmes CW, Tang JW. Increased incidence of COVID-19 in younger patients (May-July 2021) - an argument for extending vaccination? J Med Virol. Epub ahead of print. Medline:34585754 doi:10.1002/jmv.27363

78 Xue FX, Shen KL. COVID-19 in children and the importance of COVID-19 vaccination. World J Pediatr. 2021;17:462-6. Medline:34581958 doi:10.1007/s12519-021-00466-5

79 Rodewald LE, Shen KL, Yang YH, Wong GW, Namazova-Baranova L, Rosenwasser LJ, et al; Global Pediatric Pulmonology Alliance (GPPA) Expert Panel on Infectious Diseases and COVID-19. Global Pediatric Pulmonology Alliance (GPPA) proposal for COVID-19 vaccination in children. World J Pediatr. 2021;17:458-61. Medline:34586608 doi:10.1007/s12519-021-00459-4

80 Moorthy GS, Smith MJ, Staples BB. Coronavirus Disease 2019 Vaccine in Children. Pediatr Rev. 2021;42:576-8. Medline:34599060 doi:10.1542/pir.2021-004979

81 She J, Liu L, Liu W. Providing children with COVID-19 vaccinations is challenging due to lack of data and wide-ranging parental acceptance. Acta Paediatr. 2022. Epub ahead of print. Medline:34614260 doi:10.1111/apa.16137

82 Jenssen BP, Fiks AG. COVID-19 and Routine Childhood Vaccinations-Identifying Gaps and Informing Solutions. JAMA Pediatr. 2021. Epub ahead of print. Medline:34617971 doi:10.1001/jamapediatrics.2021.4248

83 Zheng YJ, Wang XC, Feng LZ, Xie ZD, Jiang Y, Lu G, et al; China National Clinical Research Center for Respiratory Diseases; National Center for Children's Health, Beijing, China; Group of Respirology, Chinese Pediatric Society, Chinese Medical Association; Chinese Medical Doctor Association Committee on Respirology Pediatrics; China Medicine Education Association Committee on Pediatrics; Chinese Research Hospital Association Committee on Pediatrics; Chinese Non-government Medical Institutions Association Committee on Pediatrics; China Association of Traditional Chinese Medicine, Committee on Children's Health and Medicine Research, Zhao ZY, Yang YH, Shen KL. Expert consensus on COVID-19 vaccination in children. World J Pediatr. 2021;17:449-57. Medline:34618327 doi:10.1007/s12519-021-00465-6

84 Dembiński Ł, Vieira Martins M, Huss G, Grossman Z, Barak S, Magendie C, et al. SARS-CoV-2 Vaccination in Children and Adolescents-A Joint Statement of the European Academy of Paediatrics and the European Confederation for Primary Care Paediatricians. Front Pediatr. 2021;9:721257. Medline:34497784 doi:10.3389/fped.2021.721257

85 Verd S, Fernández-Bernabeu M, Cardo E. The controversy surrounding vaccination of young people against COVID-19. Acta Paediatr. 2022. Epub ahead of print. Medline:34658059 doi:10.1111/apa.16156

86 Tyungu DL, O'Leary ST, Middleman AB. How can we best use COVID-19 vaccines in adolescents? A perspective from the United States. J Adolesc Health. 2021. Epub ahead of print. Medline:34666959 doi:10.1016/j.jadohealth.2021.09.008 
87 Brown KL. European pediatric societies and SARS-CoV-2 Vaccination in children under age 12: a different path in England. J Pediatr. 2021. Epub ahead of print. doi:10.1016/j.jpeds.2021.10.007

88 Shiri T, Evans M, Talarico CA, Morgan AR, Mussad M, Buck PO, et al. Vaccinating Adolescents and Children Significantly Reduces COVID-19 Morbidity and Mortality across All Ages: A Population-Based Modeling Study Using the UK as an Example. Vaccines (Basel). 2021;9:1180. Medline:34696288 doi:10.3390/vaccines9101180

89 Dyer O. Covid-19: US and China prepare for mass vaccination of children under 12. BMJ. 2021;375. Medline:34711588 doi:10.1136/bmi.n2631

90 Gurdasani D, Bhatt S, Costello A, Denaxas S, Flaxman S, Greenhalgh T, et al. Vaccinating adolescents against SARS-CoV-2 in England: a risk-benefit analysis. J R Soc Med. 2021. Epub ahead of print. Medline:34723680 doi:10.1177/01410768211052589

91 Zimmermann P, Pittet LF, Finn A, Pollard AJ, Curtis N. Should children be vaccinated against COVID-19? Arch Dis Child. 2021. Epub ahead of print.

92 Committee on Infectious Diseases. COVID-19 Vaccines in Children and Adolescents. Pediatrics. 2021. Epub ahead of print. Medline:34788344

93 Lopes-Júnior LC, Siqueira PC, Maciel ELN. School reopening and risks accelerating the COVID-19 pandemic: A systematic review and meta-analysis protocol. PLoS One. 2021;16:e0260189. Medline:34788344 doi:10.1371/journal.pone.0260189

94 Gerber JS, Offit PA. COVID-19 vaccines for children. Science. 2021;374:913. Medline:34793207 doi:10.1126/science. abn2566

95 Zhong Y, Lee LY, Tambyah PA, Liew WK, Lee BW. How can we best use COVID-19 vaccines in adolescents? An international perspective. J Adolesc Health. 2021;69:878-80. Medline:34809857 doi:10.1016/j.jadohealth.2021.08.014

96 Tanne JH. Covid-19: Cases in children rise sharply in US as doctors call for vaccine approval. BMJ. 2021;374. Medline:34400412 doi:10.1136/bmj.n2030

97 Rubin EJ, Baden LR, Grinsztejn B, Morrissey S. Audio Interview: Covid-19 in Brazil and New Evidence for Vaccinating Younger Children. N Engl J Med. 2021;385:e79. Medline:34758260 doi:10.1056/NEJMe2117854

98 Wallace M, Oliver S. COVID-19 mRNA Vaccines in Adolescents and Young Adults: Benefit-Risk Discussion. (2021). Available: https://www.cdc.gov/vaccines/acip/meetings/downloads/slides-2021-06/05-COVID-Wallace-508.pdf. Accessed: 1 November 2021.

99 Advisory Committee on Immunization Practices. ACIP Evidence to Recommendations for Use of Pfizer-BioNTech COVID-19 Vaccine under an Emergency Use Authorization. (2021). Available: https://www.cdc.gov/vaccines/acip/recs/grade/covid-19-pfizer-biontech-etr-12-15-years.html. Accessed: 29 June 2021.

100 Canadian Pediatric Society. COVID-19 Vaccine for Children. (2021). Available: https://www.cps.ca/en/documents/position/ covid-19-vaccine-for-children. Accessed: 29 June 2021.

101 Royal College of Pediatrics and Child Health. Health Policy Team. Coronavirus Vaccination Programme - Statement. (2021). Available: https://www.rcpch.ac.uk/resources/coronavirus-vaccination-programme-statement. Accessed: 29 June 2021.

102 European Centre for Disease Prevention and Control. Interim Public Health Considerations for COVID-19 Vaccination of Adolescents in the EU/EEA. (2021). Available: https://www.ecdc.europa.eu/en/publications-data/interim-public-health-considerations-covid-19-vaccination-adolescents-eueea. Accessed: 29 June 2021.

103 Goldman RD, Yan TD, Seiler M, Parra Cotanda C, Brown JC, Klein EJ, et al; International COVID-19 Parental Attitude Study (COVIPAS) Group. Caregiver willingness to vaccinate their children against COVID-19: Cross sectional survey. Vaccine. 2020;38:7668-73. Published online Oct 10, 2020. Medline:33071002 doi:10.1016/j.vaccine.2020.09.084

104 Goldman RD, Staubli G, Cotanda CP, Brown JC, Hoeffe J, Seiler M, et al. Factors associated with parents' willingness to enroll their children in trials for COVID-19 vaccination. Hum Vaccin Immunother. 2021;17:1607-11. Medline:33228458 do i:10.1080/21645515.2020.1834325

105 Zhang KC, Fang Y, Cao H, Chen H, Hu T, Chen YQ, et al. Parental Acceptability of COVID-19 Vaccination for Children Under the Age of 18 Years: Cross-Sectional Online Survey. JMIR Pediatr Parent. 2020;3:e24827. Medline:33326406 doi:10.2196/24827

106 Brandt EJ, Rosenberg J, Waselewski ME, Amaro X, Wasag J, Chang T. National Study of Youth Opinions on Vaccination for COVID-19 in the U.S. J Adolesc Health. 2021;68:869-72. Medline:33824070 doi:10.1016/j.jadohealth.2021.02.013

107 O'Leary ST, Cataldi J, Lindley MC, Beaty BL, Hurley LP, Crane LA, et al. US Primary Care Providers' Experiences and Practices Related to Routine Pediatric Vaccination During the COVID-19 Pandemic. Acad Pediatr. 2021. Epub ahead of print. Medline:34757024 doi:10.1016/j.acap.2021.10.005

108 Montalti M, Rallo F, Guaraldi F, Bartoli L, Po G, Stillo M, et al. Would Parents Get Their Children Vaccinated Against SARSCoV-2? Rate and Predictors of Vaccine Hesitancy According to a Survey over 5000 Families from Bologna, Italy. Vaccines (Basel). 2021;9:366. Medline:33920109 doi:10.3390/vaccines9040366

109 McKinnon B, Quach C, Dubé È, Tuong Nguyen C, Zinszer K. Social inequalities in COVID-19 vaccine acceptance and uptake for children and adolescents in Montreal, Canada. Vaccine. 2021;39:7140-5; Epub ahead of print. Medline:34763947 doi:10.1016/j.vaccine.2021.10.077

110 Brandstetter S, Böhmer MM, Pawellek M, Seelbach-Göbel B, Melter M, Kabesch M, et al; KUNO-Kids study group. Parents' intention to get vaccinated and to have their child vaccinated against COVID-19: cross-sectional analyses using data from the KUNO-Kids health study. Eur J Pediatr. 2021;180:3405-10. Medline:33999257 doi:10.1007/s00431-021-04094-z

111 Afifi TO, Salmon S, Taillieu T, Stewart-Tufescu A, Fortier J, Driedger SM. Older adolescents and young adults willingness to receive the COVID-19 vaccine: Implications for informing public health strategies. Vaccine. 2021;39:3473-9. Medline:34023134 doi:10.1016/j.vaccine.2021.05.026 
112 Shah S. Children and the American Rescue Plan: countering COVID-19 vaccine hesitancy during a global pandemic. Pediatr Res. 2021;90:237-9. Medline:34035429 doi:10.1038/s41390-021-01590-8

113 Sinclair S, Agerström J. Do Social Norms Influence Young People's Willingness to Take the COVID-19 Vaccine? Health Commun. 2021. Epub ahead of print. Medline:34114897 doi:10.1080/10410236.2021.1937832

114 Wang Z, She R, Chen X, Li L, Li L, Huang Z, et al. Parental acceptability of COVID-19 vaccination for children under the age of 18 years among Chinese doctors and nurses: a cross-sectional online survey. Hum Vaccin Immunother. 2021;17:332232. Medline:34137670 doi:10.1080/21645515.2021.1917232

115 Ruggiero KM, Wong J, Sweeney CF, Avola A, Auger A, Macaluso M, et al. Parents' Intentions to Vaccinate Their Children Against COVID-19. J Pediatr Health Care. 2021;35:509-17. Medline:34217553 doi:10.1016/j.pedhc.2021.04.005

116 Torjesen I. Covid-19: Vaccine centres operating at 30\% capacity as young people stay away. BMJ. 2021;374:n1808. Medline:34266863 doi:10.1136/bmj.n1808

117 Scherer AM, Gedlinske AM, Parker AM, Gidengil CA, Askelson NM, Petersen CA, et al. Acceptability of Adolescent COVID-19 Vaccination Among Adolescents and Parents of Adolescents - United States, April 15-23, 2021. MMWR Morb Mortal Wkly Rep. 2021;70:997-1003. Medline:34264908 doi:10.15585/mmwr.mm7028e1

118 Teasdale CA, Borrell LN, Kimball S, Rinke ML, Rane M, Fleary SA, et al. Plans to Vaccinate Children for Coronavirus Disease 2019: A Survey of United States Parents. J Pediatr. 2021;237:292-7. Medline:34284035 doi:10.1016/j.jpeds.2021.07.021

119 Cai H, Bai W, Liu S, Liu H, Chen X, Qi H, et al. Attitudes Toward COVID-19 Vaccines in Chinese Adolescents. Front Med (Lausanne). 2021;8:691079. Medline:34307416 doi:10.3389/fmed.2021.691079

120 Yang J, Zhang T, Qi W, Zhang X, Jia M, Leng Z, et al. COVID-19 vaccination in Chinese children: a cross-sectional study on the cognition, psychological anxiety state and the willingness toward vaccination. Hum Vaccin Immunother. 2021. Epub ahead of print. Medline:34324407 doi:10.1080/21645515.2021.1949950

121 Teasdale CA, Borrell LN, Shen Y, Kimball S, Rinke ML, Fleary SA, et al. Parental plans to vaccinate children for COVID-19 in New York city. Vaccine. 2021;39:5082-6. Medline:34340854 doi:10.1016/j.vaccine.2021.07.058

122 Wan X, Huang H, Shang J, Xie Z, Jia R, Lu G, et al. Willingness and influential factors of parents of 3-6-year-old children to vaccinate their children with the COVID-19 vaccine in China. Hum Vaccin Immunother. 2021. Epub ahead of print. Medline:34344258 doi:10.1080/21645515.2021.1955606

123 Szilagyi PG, Shah MD, Delgado JR, Thomas K, Vizueta N, Cui Y, et al. Parents' Intentions and Perceptions About COVID-19 Vaccination for Their Children: Results From a National Survey. Pediatrics. 2021. Medline:34344800 doi:10.1542/ peds.2021-052335

124 Zhang MX, Lin XQ, Chen Y, Tung TH, Zhu JS. Determinants of parental hesitancy to vaccinate their children against COVID-19 in China. Expert Rev Vaccines. 2021;20:1339-49. Medline:34376095 doi:10.1080/14760584.2021.1967147

125 Choi SH, Jo YH, Jo KJ, Park SE. Pediatric and Parents' Attitudes Towards COVID-19 Vaccines and Intention to Vaccinate for Children. J Korean Med Sci. 2021;36:e227. Medline:34402237 doi:10.3346/jkms.2021.36.e227

126 Abrams EM, Shaker M, Sinha I, Greenhawt M. COVID-19 vaccines: addressing hesitancy in young people with allergies. Lancet Respir Med. 2021;9:1090-2. Medline:34416192 doi:10.1016/S2213-2600(21)00370-2

127 Humer E, Jesser A, Plener PL, Probst T, Pieh C. Education level and COVID-19 vaccination willingness in adolescents. Eur Child Adolesc Psychiatry. 2021;1-3: Epub ahead of print. Medline:34550459 doi:10.1007/s00787-021-01878-4

128 Musa S, Dergaa I, Abdulmalik MA, Ammar A, Chamari K, Saad HB. BNT162b2 COVID-19 Vaccine Hesitancy among Parents of 4023 Young Adolescents (12-15 Years) in Qatar. Vaccines (Basel). 2021;9:981. Medline:34579218 doi:10.3390/vaccines 9090981

129 Teherani M, Banskota S, Camacho-Gonzalez A, Smith AGC, Anderson EJ, Kao CM, et al. Intent to Vaccinate SARS-CoV-2 Infected Children in US Households: A Survey. Vaccines (Basel). 2021;9:1049. Medline:34579286 doi:10.3390/vaccines9091049

130 Fazel M, Puntis S, White SR, Townsend A, Mansfield KL, Viner R, et al. Willingness of children and adolescents to have a COVID-19 vaccination: Results of a large whole schools survey in England. EClinicalMedicine. 2021;40:101144. Published online Sep 27, 2021. Medline:34608453 doi:10.1016/j.eclinm.2021.101144

131 Willis DE, Presley J, Williams M, Zaller N, McElfish PA. COVID-19 vaccine hesitancy among youth. Hum Vaccin Immunother. 2021;1-3: Epub ahead of print. Medline:34715003

132 Humble RM, Sell H, Dubé E, MacDonald NE, Robinson J, Driedger SM, et al. Canadian parents' perceptions of COVID-19 vaccination and intention to vaccinate their children: Results from a cross-sectional national survey. Vaccine. 2021. Epub ahead of print. Medline:34688500 doi:10.1016/j.vaccine.2021.10.002

133 Feng H, Zhu H, Zhang H, Cao L, Li L, Wang J, et al. Caregivers' intentions to COVID-19 vaccination for their children in China: a cross-sectional survey. Hum Vaccin Immunother. 2021. Epub ahead of print. Medline:34756123 doi:10.1080/21 645515.2021 .1985355

134 Wang X, Yan W, Lu L, Cao L, Tian Y, Zhou K. Chinese Parent Intention to Vaccinate Children With Special Diseases Against COVID-19. Front Public Health. 2021;9:725980. Medline:34778168 doi:10.3389/fpubh.2021.725980

135 Raabe VN, Lighter J, Caplan AL, Ratner AJ. Importance of Pediatric Inclusion in COVID-19 Therapeutic Trials. Clin Infect Dis. 2020;71:3248-9. Medline:32459832 doi:10.1093/cid/ciaa656

136 Mintz K, Jardas E, Shah S, Grady C, Danis M, Wendler D. Enrolling Minors in COVID-19 Vaccine Trials. Pediatrics. 2021;147:e2020040717. Medline:33334920 doi:10.1542/peds.2020-040717

137 Kampmann B. Women and children last? Shaking up exclusion criteria for vaccine trials. Nat Med. 2021;27:8. Medline:33442007 doi:10.1038/s41591-020-01199-0 
138 Couzin-Frankel J. Vaccine trials ramp up in children and adolescents. Science. 2021;371:874-5. Medline:33632828 doi:10.1126/science.371.6532.874

139 Mahase E. Covid-19: Pfizer reports 100\% vaccine efficacy in children aged 12 to 15. BMJ. 2021;373. Medline:33795232 doi:10.1136/bmj.n881

140 Wodi AP, Ault K, Hunter P, McNally V, Szilagyi PG, Bernstein H. Advisory Committee on Immunization Practices Recommended Immunization Schedule for Children and Adolescents Aged 18 Years or Younger - United States, 2021. MMWR Morb Mortal Wkly Rep. 2021;70:189-92. Medline:33571172 doi:10.15585/mmwr.mm7006al

$141 \mathrm{Li} \mathrm{J}$, Hui A, Zhang X, Yang Y, Tang R, Ye H, et al. Safety and immunogenicity of the SARS-CoV-2 BNT162bl mRNA vaccine in younger and older Chinese adults: a randomized, placebo-controlled, double-blind phase 1 study. Nat Med. 2021;27:106270. Medline:33888900 doi:10.1038/s41591-021-01330-9

142 Tanne JH. Covid-19: FDA authorises Pfizer vaccine for children 12-15. BMJ. 2021;373. Medline:33975874 doi:10.1136/ bmj.n1204

143 Wallace M, Woodworth KR, Gargano JW, Scobie HM, Blain AE, Moulia D, et al. The Advisory Committee on Immunization Practices' Interim Recommendation for Use of Pfizer-BioNTech COVID-19 Vaccine in Adolescents Aged 12-15 Years - United States, May 2021. MMWR Morb Mortal Wkly Rep. 2021;70:749-52. Medline:34014913 doi:10.15585/mmwr.mm7020e1

144 Frenck RW Jr, Klein NP, Kitchin N, Gurtman A, Absalon J, Lockhart S, et al. C4591001 Clinical Trial Group. Safety, Immunogenicity, and Efficacy of the BNT162b2 Covid-19 Vaccine in Adolescents. N Engl J Med. 2021;385:239-50. Medline:34043894 doi:10.1056/NEJMoa2107456

145 Anonymous. In brief: Pfizer/BioNTech COVID-19 vaccine authorized for adolescents 12-15 years old. Med Lett Drugs Ther. 2021;63:81. Medline:34101717

146 Glikman D, Stein M, Shinwell ES. Vaccinating children and adolescents against severe acute respiratory syndrome coronavirus 2 (SARS-CoV-2)-The Israeli experience. Acta Paediatr. 2021;110:2496-8. Medline:34159636 doi:10.1111/apa.15982

147 Han B, Song Y, Li C, Yang W, Ma Q, Jiang Z, et al. Safety, tolerability, and immunogenicity of an inactivated SARS-CoV-2 vaccine (CoronaVac) in healthy children and adolescents: a double-blind, randomised, controlled, phase 1/2 clinical trial. Lancet Infect Dis. 2021. Epub ahead of print. PMID: 34197764; PMCID: PMC8238449. Medline:34197764

148 Hause AM, Gee J, Baggs J, Abara WE, Marquez P, Thompson D, et al. COVID-19 Vaccine Safety in Adolescents Aged 12-17 Years - United States, December 14, 2020-July 16, 2021. MMWR Morb Mortal Wkly Rep. 2021;70:1053-8. Medline:34351881 doi:10.15585/mmwr.mm7031el

149 Cai C, Peng Y, Shen E, Huang Q, Chen Y, Liu P, et al. A comprehensive analysis of the efficacy and safety of COVID-19 vaccines. Mol Ther. 2021;29:2794-805. Medline:34365034 doi:10.1016/j.ymthe.2021.08.001

150 Ali K, Berman G, Zhou H, Deng W, Faughnan V, Coronado-Voges M, et al. Evaluation of mRNA-1273 SARS-CoV-2 Vaccine in Adolescents. N Engl J Med. 2021. Epub ahead of print. Medline:34379915 doi:10.1056/NEJMoa2109522

151 Wilder-Smith A, Mulholland K. Effectiveness of an Inactivated SARS-CoV-2 Vaccine. N Engl J Med. 2021;385:946-8. Medline:34469651 doi:10.1056/NEJMe2111165

152 Murthy BP, Zell E, Saelee R, Murthy N, Meng L, Meador S, et al. COVID-19 Vaccination Coverage Among Adolescents Aged 12-17 Years - United States, December 14, 2020-July 31, 2021. MMWR Morb Mortal Wkly Rep. 2021;70:1206-13. Medline:34473680 doi:10.15585/mmwr.mm7035e1

153 Lin CH. BNT162b2 Covid-19 Vaccine in Adolescents. N Engl J Med. 2021;385:1342-3. Medline:34525283 doi:10.1056/ NEJMc2113394

154 Frenck RW Jr, Dormitzer PR, Gurtman A. BNT162b2 Covid-19 Vaccine in Adolescents. [Reply]. N Engl J Med. 2021;385:1343. Medline:34525284 doi:10.1056/NEJMoa2107456

155 Xia S, Zhang Y, Wang Y, Wang H, Yang Y, Gao GF, et al. Safety and immunogenicity of an inactivated COVID-19 vaccine, BBIBP-CorV, in people younger than 18 years: a randomised, double-blind, controlled, phase 1/2 trial. Lancet Infect Dis. 2021. Epub ahead of print. Medline:34536349 doi:10.1016/S1473-3099(21)00462-X

156 Zhu F, Jin P, Zhu T, Wang W, Ye H, Pan H, et al. Safety and immunogenicity of a recombinant adenovirus type-5-vectored COVID-19 vaccine with a homologous prime-boost regimen in healthy participants aged 6 years and above: a randomised, double-blind, placebo-controlled, phase 2b trial. Clin Infect Dis. 2021. Epub ahead of print. Medline:34551104 doi:10.1093/ $\mathrm{cid} / \mathrm{ciab} 845$

157 Dooling K, Gargano JW, Moulia D, Wallace M, Rosenblum HG, Blain AE, et al. Use of Pfizer-BioNTech COVID-19 Vaccine in Persons Aged $\geq 16$ Years: Recommendations of the Advisory Committee on Immunization Practices - United States, September 2021. MMWR Morb Mortal Wkly Rep. 2021;70:1344-8. Medline:34555007 doi:10.15585/mmwr.mm7038e2

158 Glatman-Freedman A, Hershkovitz Y, Kaufman Z, Dichtiar R, Keinan-Boker L, Bromberg M. Effectiveness of BNT162b2 Vaccine in Adolescents during Outbreak of SARS-CoV-2 Delta Variant Infection, Israel, 2021. Emerg Infect Dis. 2021;27:291922. Medline:34570694 doi:10.3201/eid2711.211886

159 Hill HA, Yankey D, Elam-Evans LD, Singleton JA, Sterrett N. Vaccination Coverage by Age 24 Months Among Children Born in 2017 and 2018 - National Immunization Survey-Child, United States, 2018-2020. MMWR Morb Mortal Wkly Rep. 2021;70:1435-40. Medline:34648486 doi:10.15585/mmwr.mm704lal

160 Glikman D, Stein M, Shinwell ES. Vaccinating children and adolescents against severe acute respiratory syndrome corona virus 2 (SARS-CoV-2), updated data from Israel. Acta Paediatr. 2022. Epub ahead of print. Medline:34657316 doi:10.1111/ apa.16157

161 Olson SM, Newhams MM, Halasa NB, Price AM, Boom JA, Sahni LC, et al; Overcoming COVID-19 Investigators. Effectiveness of Pfizer-BioNTech mRNA Vaccination Against COVID-19 Hospitalization Among Persons Aged 12-18 Years - United 
States, June-September 2021. MMWR Morb Mortal Wkly Rep. 2021;70:1483-8. Medline:34673751 doi:10.15585/mmwr. $\mathrm{mm} 7042 \mathrm{el}$

162 Lv M, Luo X, Shen Q, Lei R, Liu X, Liu E, et al. Safety, Immunogenicity, and Efficacy of COVID-19 Vaccines in Children and Adolescents: A Systematic Review. Vaccines (Basel). 2021;9:1102. Medline:34696210 doi:10.3390/vaccines9101102

163 Tanne JH. Covid-19: US doctors begin administering vaccine to children aged 5-11. BMJ. 2021;375. Medline:34737205 doi:10.1136/bmj.n2693

164 Walter EB, Talaat KR, Sabharwal C, Gurtman A, Lockhart S, Paulsen GC, et al. C4591007 Clinical Trial Group. Evaluation of the BNT162b2 Covid-19 Vaccine in Children 5 to 11 Years of Age. N Engl J Med. 2021. Epub ahead of print. Medline:34752019 doi:10.1056/NEJMoa2116298

165 Hageman JR, Alcocer Alkureishi L. The Status of the COVID-19 Vaccines for Children Age 5 to 11 Years. Pediatr Ann. 2021;50:e444-5. Medline:34757881 doi:10.3928/19382359-20211025-02

166 Woodworth KR, Moulia D, Collins JP, Hadler SC, Jones JM, Reddy SC, et al. The Advisory Committee on Immunization Practices' Interim Recommendation for Use of Pfizer-BioNTech COVID-19 Vaccine in Children Aged 5-11 Years - United States, November 2021. MMWR Morb Mortal Wkly Rep. 2021;70:1579-83. Medline:34758012 doi:10.15585/mmwr.mm7045el

167 Wise J. Covid-19: Pfizer vaccine provides 90\% protection against infection in children aged 5-11, study finds. BMJ. 2021;375. Medline:34758974 doi:10.1136/bmj.n2746

168 Kuehn BM. COVID-19 Vaccine Highly Effective Against Adolescent Hospitalizations. JAMA. 2021;326:2002. Medline:34812857 doi:10.1001/jama.2021.20143

169 Reis BY, Barda N, Leshchinsky M, Kepten E, Hernán MA, Lipsitch M, et al. Effectiveness of BNT162b2 Vaccine against Delta Variant in Adolescents. N Engl J Med. 2021;385:2101-3. Medline:34670036 doi:10.1056/NEJMc2114290

170 Snapiri O, Rosenberg Danziger C, Shirman N, Weissbach A, Lowenthal A, Ayalon I, et al. Transient Cardiac Injury in Adolescents Receiving the BNT162b2 mRNA COVID-19 Vaccine. Pediatr Infect Dis J. 2021;40:e360-3. Medline:34077949 doi:10.1097/INF.0000000000003235

171 Marshall M, Ferguson ID, Lewis P, Jaggi P, Gagliardo C, Collins JS, et al. Symptomatic Acute Myocarditis in 7 Adolescents After Pfizer-BioNTech COVID-19 Vaccination. Pediatrics. 2021;148:e2021052478. Medline:34088762 doi:10.1542/peds.2021052478

172 Abu Mouch S, Roguin A, Hellou E, Ishai A, Shoshan U, Mahamid L, et al. Myocarditis following COVID-19 mRNA vaccination. Vaccine. 2021;39:3790-3. Medline:34092429 doi:10.1016/j.vaccine.2021.05.087

173 Gargano JW, Wallace M, Hadler SC, Langley G, Su JR, Oster ME, et al. Use of mRNA COVID-19 Vaccine After Reports of Myocarditis Among Vaccine Recipients: Update from the Advisory Committee on Immunization Practices - United States, June 2021. MMWR Morb Mortal Wkly Rep. 2021;70:977-82. Medline:34237049 doi:10.15585/mmwr.mm7027e2

174 Takemoto C. Thrombosis with COVID-19: kids get it too. Blood. 2021;138:109-11. Medline:34264277 doi:10.1182/ blood.2021011149

175 Tano E, San Martin S, Girgis S, Martinez-Fernandez Y, Sanchez Vegas C. Perimyocarditis in Adolescents After Pfizer-BioNTech COVID-19 Vaccine. J Pediatric Infect Dis Soc. 2021. Epub ahead of print. Medline:34319393 doi:10.1093/jpids/piab060

176 Long SS. Important Insights into Myopericarditis after the Pfizer mRNA COVID-19 Vaccination in Adolescents. J Pediatr. 2021;238:5. Medline:34332972 doi:10.1016/j.jpeds.2021.07.057

177 Das BB, Kohli U, Ramachandran P, Nguyen HH, Greil G, Hussain T, et al. Myopericarditis after messenger RNA Coronavirus Disease 2019 Vaccination in Adolescents 12 to 18 Years of Age. J Pediatr. 2021;238:26-32.el. Medline:34339728 doi:10.1016/j.jpeds.2021.07.044

178 Perry RJ, Tamborska A, Singh B, Craven B, Marigold R, Arthur-Farraj P, et al; CVT After Immunisation Against COVID-19 (CAIAC) collaborators. Cerebral venous thrombosis after vaccination against COVID-19 in the UK: a multicentre cohort study. Lancet. 2021;398:1147-56. Medline:34370972 doi:10.1016/S0140-6736(21)01608-1

179 Dionne A, Sperotto F, Chamberlain S, Baker AL, Powell AJ, Prakash A, et al. Association of Myocarditis With BNT162b2 Messenger RNA COVID-19 Vaccine in a Case Series of Children. JAMA Cardiol. 2021. Epub ahead of print. Medline:34374740 doi:10.1001/jamacardio.2021.3471

180 Jain SS, Steele JM, Fonseca B, Huang S, Shah S, Maskatia SA, et al. COVID-19 Vaccination-Associated Myocarditis in Adolescents. Pediatrics. 2021;148:e2021053427. Medline:34389692 doi:10.1542/peds.2021-053427

181 Mark C, Gupta S, Punnett A, Upton J, Orkin J, Atkinson A, et al. Safety of administration of BNT162b2 mRNA (Pfizer-BioNTech) COVID-19 vaccine in youths and young adults with a history of acute lymphoblastic leukemia and allergy to PEGasparaginase. Pediatr Blood Cancer. 2021;68:e29295. Medline:34398511 doi:10.1002/pbc.29295

182 King H, Deshpande S, Woodbridge T, Hilliard T, Standing J, Lewis M, et al. Initial experience of the safety and tolerability of the BNT162b2 (Pfizer-Bio-N-Tech) vaccine in extremely vulnerable children aged 12-15 years. Arch Dis Child. 2021. Epub ahead of print. Medline:34446440 doi:10.1136/archdischild-2021-322655

183 Kuehn BM. Adolescent Myocarditis After COVID-19 Vaccination Is Rare. JAMA. 2021;326:902. Medline:34519795 doi:10.1001/jama.2021.14237

184 Calcaterra G, Mehta JL, de Gregorio C, Butera G, Neroni P, Fanos V, et al. COVID 19 Vaccine for Adolescents. Concern about Myocarditis and Pericarditis. Pediatr Rep. 2021;13:530-3. Medline:34564344 doi:10.3390/pediatric13030061

185 Ambati S, Colon M, Mihic M, Sanchez J, Bakar A. Acute Myopericarditis after COVID-19 Vaccine in Teenagers. Case Rep Cardiol. 2021;2021:8268755. Medline:34589238 doi:10.1155/2021/8268755

186 Mevorach D, Anis E, Cedar N, Bromberg M, Haas EJ, Nadir E, et al. Myocarditis after BNT162b2 mRNA Vaccine against Covid-19 in Israel. N Engl J Med. 2021. Epub ahead of print. Medline:34614328 doi:10.1056/NEJMoa2109730 
187 Paterlini M. Covid-19: Sweden, Norway, and Finland suspend use of Moderna vaccine in young people "as a precaution". BMJ. 2021;375. Medline:34635488 doi:10.1136/bmj.n2477

188 Nakazawa E, Uchimura T, Hirai Y, Togashi H, Oyama Y, Inaba A, et al. New-onset pediatric nephrotic syndrome following Pfizer-BioNTech SARS-CoV-2 vaccination: a case report and literature review. CEN Case Rep. 2021;1-5: Epub ahead of print. Medline:34782983 doi:10.1007/s13730-021-00656-0

189 Alamer E, Alhazmi A, Qasir NA, Alamer R, Areeshi H, Gohal G, et al. Side Effects of COVID-19 Pfizer-BioNTech mRNA Vaccine in Children Aged 12-18 Years in Saudi Arabia. Vaccines (Basel). 2021;9:1297. Medline:34835228 doi:10.3390/vaccines9111297

190 Buchhorn R, Meyer C, Schulze-Forster K, Junker J, Heidecke H. Autoantibody Release in Children after Corona Virus mRNA Vaccination: A Risk Factor of Multisystem Inflammatory Syndrome? Vaccines (Basel). 2021;9:1353. Medline:34835284 doi:10.3390/vaccines9111353

\section{Correspondence to:}

Professor Igor Rudan, FRSE

Centre for Global Health

The Usher Institute, The University of Edinburgh

30 West Richmond Street

Edinburgh, EH8 9DX,

Igor.Rudan@ed.ac.uk 